This item was submitted to Loughborough's Research Repository by the author.

Items in Figshare are protected by copyright, with all rights reserved, unless otherwise indicated.

\title{
Empirical and computational evidence for thermal mass assessment: The example of insulating concrete formwork
}

PLEASE CITE THE PUBLISHED VERSION

https://doi.org/10.1016/j.enbuild.2019.02.021

PUBLISHER

(C) Elsevier BV

VERSION

AM (Accepted Manuscript)

PUBLISHER STATEMENT

This paper was accepted for publication in the journal Energy and Buildings and the definitive published version is available at https://doi.org/10.1016/j.enbuild.2019.02.021

LICENCE

CC BY-NC-ND 4.0

\section{REPOSITORY RECORD}

Mantesi, Eirini, Christina Hopfe, Konstantinos Mourkos, Jacqui Glass, and Malcolm Cook. 2019. "Empirical and Computational Evidence for Thermal Mass Assessment: The Example of Insulating Concrete Formwork". figshare. https://hdl.handle.net/2134/37060. 


\title{
Empirical and Computational Evidence for Thermal Mass Assessment: The Example of Insulating Concrete Formwork
}

\author{
Eirini Mantesi a, Christina J. Hopfe a, Konstantinos Mourkos a , Jacqueline Glass ${ }^{1}$ a, \\ Malcolm Cook ${ }^{\text {a }}$ \\ ${ }^{a}$ School of Architecture, Building and Civil Engineering, Loughborough University, Leicestershire \\ LE11 3TU, UK
}

\section{KEYWORDS}

Thermal Monitoring; Empirical Validation; Calibrated Simulation; Dynamic Heat Transmission; Sensitivity Analysis; Benchmarking; Internal Air Temperature; Transient Energy Ratio

\begin{abstract}
Insulated Concrete Formwork (ICF) is a site-based Modern Method of Construction (MMC). As a MMC, ICF has several advantages; increased speed of construction, cost and defect reduction, safety, among others. Moreover, the ICF wall construction method has similar benefits to any other heavyweight structure (such as strength, durability, noise attenuation). However, its thermal performance is not yet well-researched and understood. Using computational analysis and empirical evaluation, the aim of this research was to analyse the thermal performance of an existing ICF building; and to develop evidence about its transient thermal behaviour and how the latter is affected by the inherent thermal inertia of the concrete core. The results demonstrated that the ICF fabric showed a slow response to changes in boundary conditions, providing a stable internal environment. The concrete core of ICF was found to act as a buffer to the heat flow, reducing the transmission losses by $37 \%$, compared to a lightweight wall with equivalent insulation. The analysis showed that although ICF is mostly considered as an insulated panel, the element's thermal mass is not as decoupled from the internal space, as has been thought the case.
\end{abstract}

\section{Introduction}

Improved building fabric performance (reduced infiltration, better insulation and optimal use of solar gains) is a primary consideration to reduce energy consumption in the built environment [1]. The thermal mass of a building's fabric can be used as a passive design strategy to reduce energy use for space conditioning [2][3][4][5][6]. The term thermal mass defines the ability of a material to store sensible thermal energy by changing its temperature. The amount of thermal

\footnotetext{
${ }^{1}$ Present address: The Bartlett School of Construction \& Project Management, UCL, London, WC1E 7HB, UK.
} 
energy storage is proportional to the difference between a material's final and initial temperatures, its density, and its specific heat capacity[7]. In simple terms the thermal mass (or thermal storage capacity) of the building fabric is its ability to capture and store casual and solar heat gains during time of surplus, disseminating the stored heat at time of scarcity[2]. In this way the building fabric helps to moderate internal temperature swings and shifts (delays) the time that the peak load occurs, resulting ultimately in reduced energy use for space conditioning[8][3][9]. All building construction methods can broadly be categorised as lightweight, medium weight and heavyweight, according to the level of thermal mass in the building fabric [8].

\subsection{Insulated Concrete Formwork as a heavyweight Modern Method of Construction}

The UK housing construction industry has been characterised as conservative with very little changes noticed in the building design, construction and layout over the past 100 years [10] [11]. However, a recent industry survey conducted by the National House Building Council (NHBC) [12] indicated that there is a noticeable turn toward lightweight and other off-site Modern Methods of Construction (MMC) due to their advantages in reducing cost, time, and defects. ICF is categorised as one of the site-based MMC [10]. The ICF wall component consists of modular prefabricated Expanded Polystyrene Insulation (EPS) hollow blocks and cast in situ concrete. The hollow blocks are assembled on site and the concrete is poured into the void. Once the concrete has cured, the insulating formwork stays in place permanently. The resulting construction structurally resembles a conventional reinforced concrete wall. The ICF wall system has several advantages; it shows an increased speed of construction, a significant structural strength and durability, and better noise attenuation. With regards to its thermal performance, ICF can provide complete external and internal wall insulation, minimising thermal bridging, providing very low U-values and high levels of air-tightness, if installed correctly [13].

ICF is often thought of as an insulated panel, acting thermally as a lightweight structure. There is a view that the internal layer of insulation isolates the thermal mass (say, of the concrete) from the internal space and interferes with thermal interaction. Despite evidence supporting ICF's thermal storage capacity (compared to a lightweight timber-frame panel with equivalent insulation), there remains an important shortcoming in knowledge of how ICF operates thermally, in this case, there is a generally poor level of understanding of how to quantify the effect of the thermal mass within ICF. Several field and computational studies have been conducted in the past, mainly in the USA and Canada, aiming to investigate the benefits of the inherent thermal mass located at the core of ICF. The National Association of Home Builders (NAHB) Research Centre conducted a field study in Maryland, USA to evaluate the energy consumption of three side-by-side houses, two ICF houses and one built with timber-frame walls [14]. The houses were identical (apart from the external wall construction) unoccupied and built for the purposes of the study. The results showed that the two ICF houses performed much better than the timber-frame building, requiring on average $20 \%$ less energy for space 
conditioning. However, the authors suggested that this difference was mostly attributed to the different thermal resistance (R-value) of the walls and that the contribution of the ICF thermal mass was negligible. Similar conclusions were drawn by Hill and Monsour [15], who performed a monitoring project to characterise the thermal performance of ICF and its airtightness in a residential building located in Ontario, Canada. By placing temperature sensors and taking heat flux measurements, the aim was to record the transient temperature behaviour of the ICF wall. Subsequently, a computational comparative analysis was performed (using eQUEST) and the as-built scenario was compared to a theoretical model without thermal mass (resembling a timber-frame structure). The authors concluded that there were insignificant improvements in terms of energy consumption between the ICF and timber-frame buildings. Armstrong et al. [16] conducted a field monitoring study on the dynamic heat transmission through an ICF wall in Canada. In contrast to the previous two studies, the authors concluded that during transient conditions, the concrete core of ICF played a significant role in tempering heat losses to the exterior. The thermal mass of the concrete has been shown to reduce the peak heat flux through the assembly during cold weather.

Gajda and VanGeem [17] conducted a computational analysis using DOE2.6 simulation program to compare the energy use in a typical house for five different locations across the USA, and for three different wall configurations; a conventional timber-frame wall, an ICF wall and a non-mass "ICF" wall (according to the minimum energy code requirements). The results indicated that in all locations the ICF wall showed higher energy savings compared to the other two walls. In the comparison of ICF to timber-frame the savings reached up to $9 \%$. However, a limitation of this study was that the two different walls under investigation had different thermal resistances (R-values), hence a direct comparison could not provide feedback on the contribution of the ICF's thermal mass solely on the aforementioned energy savings. Kosny et al. [18] performed a comparative computational analysis (using DOE-2) on the energy performance of lightweight and massive walls (including ICF) and calculated the potential energy savings for 10 different locations in USA climates. They concluded that among the high thermal mass configurations, the thermal performance of ICF was in between the thermal performance of the externally insulated and the internally insulated concrete wall and performed worse than a sandwich panel, where the insulation would be located at the middle of the wall. In the comparison of ICF to conventional timber-frame wall, the results showed that ICF can provide between $6 \%$ and $8 \%$ energy savings. However, similarly to the previous study, the R-values of the two walls were not equal. As a result, it is not possible to distinguish exactly which part of the energy savings are attributed to the thermal mass and which part is because of the enhanced fabric resistance of the ICF wall. Saber et al. [19] investigated (using numerical analysis) the contribution of ICF thermal mass due to the concrete layer compared to a theoretical "ICF" wall without concrete and equal R-value for the cold climate of Ottawa, Canada. The results showed that the thermal mass of the 
concrete core can lead to up $6 \%$ savings in heating loads, compared to the same wall without the concrete layer. Hart et al. [20] used simulation (EnergyPlus) to analyse the variation in energy end-use for a set of different wall types across different climate zones in the USA. The study compared externally and internally insulated concrete walls, ICF and timber-frame walls. With regards to ICF, the analysis showed that the energy use of ICF falls between the energy consumptions of externally and internally insulated concrete walls and always performs better than a timber-frame wall with equal levels of insulation. Rajagopalan et al. [13] performed a comparative life cycle assessment (LCA) of wall sections comprised of ICF and timber-frame for the whole life cycle phases of a buildings, from raw materials to manufacturing, construction, use and end of life phases. They concluded that ICF has a higher embodied carbon than traditional timber-frame wall during manufacturing phase. Yet, the ICF showed reduced energy consumption during the use phase of the buildings, meaning that the overall environmental footprint of the ICF building could be outweighed by benefits achieved in terms of energy savings during the operational phase of the building.

Very few studies have considered the accuracy of ICF simulation in current building performance simulation (BPS) tools and software [21][22][23][24][25]. Kosny and Kossecka [21] investigated the limitations associated to onedimensional heat transfer analysis adopted in many of current simulation programs and proposed a method of implementing three-dimensional heat transfer modelling within whole building simulation tools. They proposed the concept of "equivalent wall", expressing the role of storage effects in heat flow through an element and tested the accuracy of this method against one-dimensional heat transfer and accurate three-dimensional model (using finite difference modelling). They found that for simple low thermal mass wall assemblies (such as timber-frame walls) the difference between one-dimensional and 3-dimensional heat transfer modelling was below 2\%. However, for complex wall assemblies (such as ICF), the difference was in instances up to 27\%. Mantesi et al. [25] investigated the "modelling gap", namely the impact of default settings and the implications of the various calculation algorithms on the results divergence in thermal mass simulation using different tools. Three different construction methods were included in their analysis; ICF, low thermal mass (timber-frame) and high thermal mass (concrete wall). The results indicated that the modelling uncertainties accounted for up to $26 \%$ variation in the simulation predictions (annual heating of the ICF building), if the user relies on the default settings of the tools.

All of the previous studies presented in this section analysed the thermal performance of ICF, using either simulation or field measurements of test rigs. Fewer studies have combined simulation and monitoring results, and these have focused on the transient performance of the ICF wall assembly, measuring solely surface temperatures and heat flux of the ICF fabric. None of the aforementioned studies has considered internal thermal conditions and the energy consumption of an existing occupied ICF building. 


\subsection{Aim of the research}

To the authors' knowledge this is the first whole building monitoring study conducted in a real ICF occupied detached building in Europe (namely in the UK), which combines computational analysis and empirical data. Although ICF dates back in Europe to the late 1960's [16], it is often characterised as an innovative wall technology because it has only recently become more popular for use in residential and commercial construction. Additionally, an ICF building shows significantly increased speed of construction, compared to traditional construction methods; hence ICF is often classed among the MMCs.

Using both empirical data and computational analysis, this study aims to find evidence with respect to the thermal storage capacity of the ICF concrete core and to demonstrate whether an ICF building could be characterised as a thermally heavyweight or lightweight structure. Furthermore, the combined analysis of monitoring and simulation results allows the accuracy of simulation predictions to be empirically evaluated. With the use of calibrated models (based on the monitoring data), the as-built scenario is compared to other known wall constructions with a degree of confidence in the reliability of predictions, aiming to assess its thermal performance against alternative high and low thermal mass constructions

\section{Methodology}

The study was conducted in three phases. Phase 1 comprised the thermal monitoring of the selected ICF building case study. In phase 2 information from the monitoring was used to calibrate a simulation model, created using EnergyPlus 8.6. Then the monitoring data were plotted against simulation predictions to quantify their divergence and to empirically assess the accuracy of simulation predictions. The Root Mean Square Error (RMSE) and the Mean Biased Error (MBE) as shown in the following equations were used to calculate the error between monitoring and simulation results [26].

$$
\begin{gathered}
R M S E=\sqrt{\frac{\sum_{i=1}^{N}\left(m_{i}-s_{i}\right)^{2}}{N}} \\
M B E(\%)=\frac{\sum_{i=1}^{N}\left(m_{i}-s_{i}\right)}{\sum_{i=1}^{N} m_{i}}
\end{gathered}
$$

Where,

RMSE is the root mean square error

MBE is the mean biased error

$\mathrm{m}_{\mathrm{i}}$ and $\mathrm{s}_{\mathrm{i}}$ are the respective measured and simulated data points for each model instance time step

$\mathrm{N}$ is the number of data points 
Moreover, the diurnal internal and external temperature variations were used to calculate the decrement factor $\left(\mathrm{D}_{\mathrm{f}}\right)$ and the decrement delay $(\omega)$ of the building [8].

$$
D_{f}=\frac{t_{i, a m p}}{t_{e, a m p}}
$$

Where,

$\mathrm{D}_{\mathrm{f}}$ is the decrement factor

$t_{e, a m p}$ is the amplitude of the external temperature sine wave $(\mathrm{K})$

$t_{\mathrm{i}, \text { amp }}$ is the amplitude of the internal temperature sine wave $(\mathrm{K})$

$$
\omega=T_{t i, \max }-T_{t e, \max }
$$

Where,

$\omega$ is the decrement delay (Hours)

$\mathrm{T}_{\mathrm{t}, \mathrm{max}}$ is the time of the maximum internal temperature (Hours)

$\mathrm{T}_{\mathrm{te}, \mathrm{max}}$ is the time of the maximum external temperature (Hours)

In phase 3, three different wall constructions were compared among each other, ICF, high thermal mass (HTM) and low thermal mass (LTM). For ease of reference, these will be referred to as ICF, HTM and LTM from this point forward.

\subsection{Case study building}

Monitoring data were gathered from an ICF low-energy dwelling, designed to achieve near Passivhaus levels (Fig.1a). The case study is a two storey, three-bedroom house of approximately $250 \mathrm{~m}^{2}$, located in the wider area of Guildford, Surrey in a rural settlement called Gomshall, in the UK. The building envelope uses ICF walls, an insulated foundation raft, a prefabricated concrete hollow-core slab, and prefabricated EPS roof panels.

The county of Surrey has a temperate maritime climate with typically warm rather than hot summers and cool to cold winters. On average the hottest month is July in summer and the coldest is January in winter [27]. Indicative values of the local climate are shown in Table 1. 
a)

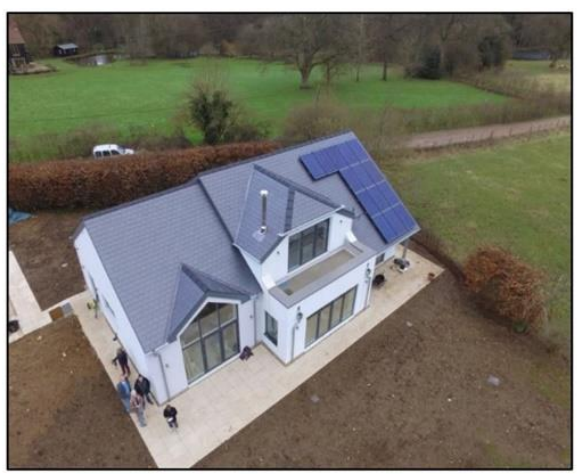

c)

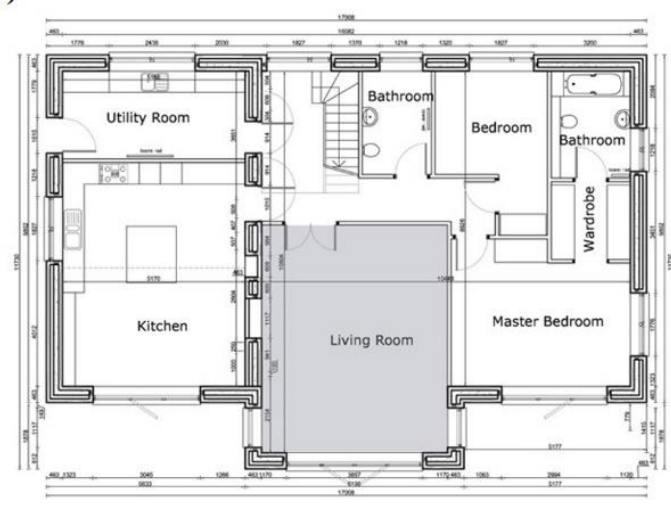

b)

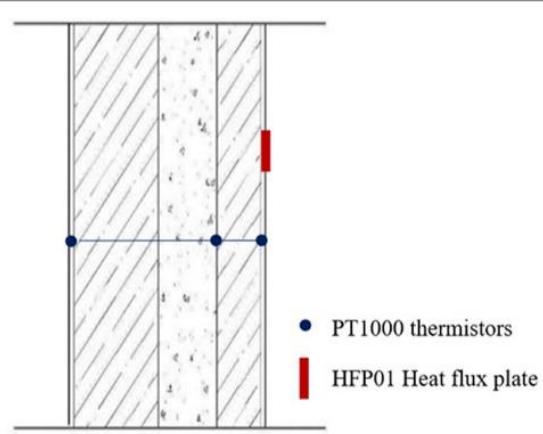

d)

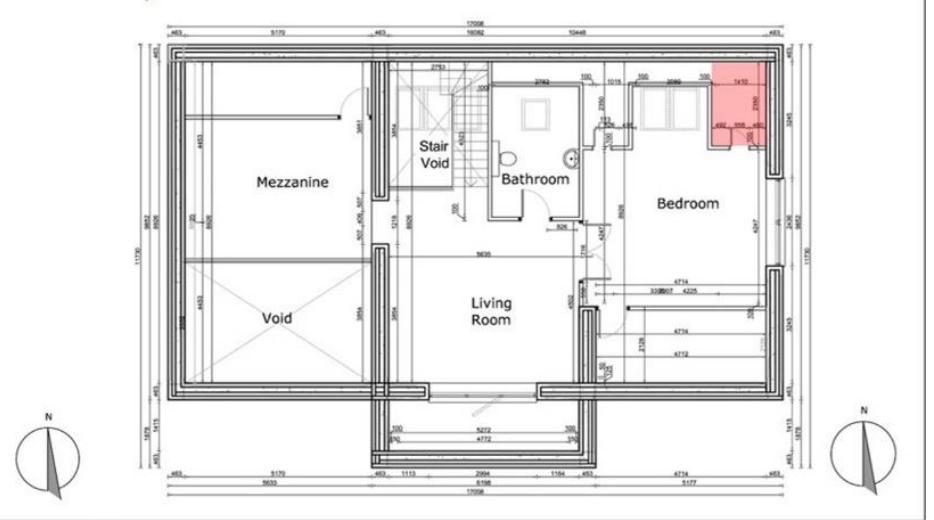

Figure 1: The case study building: a) South-West view of the building, b) Cross-section of ICF wall showing location of the surface temperature and heat flux sensors, c) Ground-floor plan and d) First-floor plan of the building.

Table 1: Indicative values of climate data for Guildford, Surrey, UK [27], [28].

\begin{tabular}{|c|c|}
\hline \multicolumn{2}{|c|}{ WEATHER DATA } \\
\hline Dry Bulb Minimum Temperature $\left(\mathrm{C}^{\circ}\right)$ & 6.5 \\
\hline Dry Bulb Maximum Temperature $\left(\mathrm{C}^{\circ}\right)$ & 15.0 \\
\hline Heating degree days $^{2}\left(\right.$ at $\left.15.5^{\circ} \mathrm{C}\right)$ & 1924.7 \\
\hline Cooling degree days (at $\left.15.5^{\circ} \mathrm{C}\right)$ & 487.6 \\
\hline Sunshine (hours per annum) & 1564.2 \\
\hline Rainfall (mm per annum) & 656.6 \\
\hline Mean wind speed at $10 \mathrm{~m}(\mathrm{knots})$ & 5.0 \\
\hline
\end{tabular}

The monitoring study lasted for approximately 20 months, between April 2016 and February 2018. The recorded data comprised the following:

- On-site weather data

- Surface and intra-fabric temperatures of the external walls

- Heat fluxes of the building fabric

\footnotetext{
${ }^{2}$ In the UK, degree-days are published to a traditional base temperature of $15.5^{\circ} \mathrm{C}$ [28].
} 
- Internal air temperatures

- Internal relative humidity

- $\mathrm{CO}_{2}$ levels

- Energy consumption

- Windows opening and closing activity

Weather data (i.e. dry-bulb temperature, dew point, relative humidity, atmospheric pressure, wind speed and direction) were recorded on site at a one minute time step [29]. An irradiance sensor (pyranometer) was also installed on site to record global solar radiation (again, at a one minute resolution) [30]. The Perez model was used in EnergyPlus to split global solar radiation into direct normal and diffuse horizontal components [31][32]. Surface temperatures were recorded on the north facing wall using PT1000 thermistors. Three thermistors were installed across the ICF wall section; one in the external surface of the external layer of insulation, one in the interface between the concrete core and the internal layer of insulation and one at the internal surface of the ICF wall (Fig.1b). Heat flux measurements were also conducted on the internal surface of the North ICF wall, using thermophile flux sensors [33]. Both surface temperatures and heat flux measurements were recorded in a two-minute time step resolution. Internal air temperature and relative humidity were recorded in all rooms, every 15 minutes, using HOBO U12 stand-alone loggers [34].

The analysis reported here considers two periods, one week in the summer of 2016 (07 - 13 July 2016) and one week in spring of $2017\left(14-20\right.$ April $\left.2017^{3}\right)$, both of which were at times when the house was unoccupied ${ }^{4}$. The aim being to reduce the level of uncertainty and investigate how the fabric would perform (with regard to internal air temperatures) under a free-floating mode, without the influence of other parameters (such as HVAC operation, mechanical ventilation, occupancy, user behaviour, etc). The results of internal air temperatures were presented for the ground floor living room, indicated in Fig.1c as the grey-shaded area. The room is south-facing and has a large opening on the south wall (without shading) and two more windows on its east and west walls. Heat flux and surface temperatures were measured at the north wall of the first floor, north facing storage room (indicated as the red-shaded area in Fig.1d). The room had no windows and it was unheated throughout the monitoring period.

\footnotetext{
${ }^{3}$ The ambient temperatures during the month of April 2017 were low enough to consider this period as a representative winter period. However, the solar radiation availability was relatively high compared to a typical winter week, resulting in higher internal temperatures than one would expect when the house operates in free-floating mode (no space conditioning).

${ }^{4}$ Although the building was unoccupied during the summer week under investigation, the MVHR system was running on constant low speed and air flow rates, to prevent heat accumulation.
} 


\subsection{Model settings and calibration}

The simulation model of the building case study was created using EnergyPlus 8.6 [32]. EnergyPlus is an open-source, freeware, validated and commonly used dynamic BPS tool, developed by the Department of Energy (DOE) in the USA. In [25], the authors investigated the impact of default settings and the implications of the various calculation algorithms on the simulation of thermal mass when using different BPS tools. EnergyPlus was selected for the analysis presented in this paper, as it offers significant flexibility to the user, through changing from default to advanced settings. Eight other BPS tools were considered and discounted [23]. In that respect, the calculation algorithms regarding convection coefficient calculation, conduction heat transfer calculation and solar distribution were selected to match closely the actual building performance. Being a heavyweight structure, the conduction heat transfer was simulated using the finite difference algorithm. The solar distribution was simulated using the full interior and exterior algorithm, where the program calculates the amount of beam radiation falling on each surface of the zone, including floors, walls and windows, by projecting the sun's rays through the transparent surfaces. Finally, the appropriate convection coefficient algorithms were chosen according to the operation of the building for each of the analysed periods. The external convection coefficients were calculated using the DOE-2 algorithm for rough surfaces. The internal convection coefficients were calculated based on mixed and forced convection model for ceiling diffuser during the summer period (when the MVHR was running on constant low speed and air flow rates) and based on the temperature difference (TARP algorithm) during spring period, when the house was running with no mechanical ventilation [32].

Information from the thermal monitoring project regarding on-site recorded weather data, occupancy patterns and the use of MVHR and gas heating systems (for the spring period) was used to calibrate the simulation model. Reddy [35, p.1] described calibrated simulation as "the process of using an existing building simulation computer program and "tuning” or calibrating the various inputs to the program so that observed energy use matches closely with that predicted by the simulation program." Once calibrated simulation is achieved, more reliable simulation predictions can be made [36]. Calibrated simulation is usually a very useful tool to explore hypothetical, alternative design and operational scenarios and measuring the savings of conservation retrofits to existing buildings [37],[36].

The model was found to be sensitive to three main parameters, the zone internal heat gains, the infiltration rates and the ventilation flow rates of the MVHR. Infiltration rates were predicted utilising data from the leakage test that was conducted on the building; according to this test, the effective leakage area (ELA) @ 4Pa was found to be equal to $0.39 \mathrm{~cm}^{2} / \mathrm{m}^{2}$. This was used as an input to the simulations by multiplying this value with the exposed area of each thermal zone. However, during the test the MVHR unit was not in operation. Under actual conditions, when the MVHR unit is on, the infiltration rates may be different [38]. Since, the interaction between the MVHR and the airtightness of the 
building was not considered in the simulations, the ventilation flow rates were used as a variable in the calibration process. The analysis was focused on two unoccupied periods (to investigate the performance of the fabric in freefloating mode), however the simulation models were calibrated against occupancy patterns (internal heat gains from lighting, appliances and occupants), and heating setpoints/schedules for the weeks preceding the unoccupied periods. The calibration process was performed using the manual iterative technique [35],[26],[39],[40] in which the user of the BPS tool adjusts the input parameters on a trial-and-error basis until the model output matches the recorded data.

\subsection{Comparative analysis}

The ICF simulation model was used as a base-case, two additional models were created, the HTM and the LTM case. The only difference among the models was the construction of the external walls. Since the aim was to investigate the impact of the walls' thermal mass on thermal performance, the thermal transmittance (U-value) was kept consistent in all three models to allow a direct comparison. Details of the material properties of all three construction methods are included in Table A.1 in the Appendix. A comparative analysis was performed on the performance of the three wall construction methods, focusing on internal air temperatures and on the dynamic characteristics of the fabric $\left(D_{f}-\right.$ Eq. 3 and $\omega$-Eq. 4) as calculated based on the diurnal internal temperature variation in each of the three buildings.

Initially, all three buildings were identical, the only difference was the level of thermal mass in the walls. However, it was essential to quantify the impact of heavyweight floors and interior thermal mass on the internal environment stabilisation. To do that, a parametric analysis was performed on the construction of the ground floor for the ICF building. Three different levels of thermal mass were employed for the floor, varying from lightweight to medium and heavyweight constructions. Details of the three different floor constructions can be found in Table A.2 in the Appendix. The results were plotted against a lightweight floor for the LTM building and a heavyweight floor for the HTM building, both representing conventional construction methods of the UK housing industry.

Furthermore, Monte Carlo-based global uncertainty analysis (UA) was used to assess the role of the interior thermal mass (due to furnishing) on the internal temperatures of the space. Latin Hypercube Sampling ${ }^{5}$ (LHS) method was employed as a sampling method to generate sampled variables desirable for the UA [41],[42],[43] using SimLab 2.2.1 [44]. All physical properties of the internal furnishing were assigned a mean $(\mu)$ based on information found in literature [45] and a uniform distribution, with a fixed relative range of $50 \%{ }^{6}$. Details on the mean, minimum and maximum values

\footnotetext{
${ }^{5}$ The LHS is a probabilistic sampling procedure that incorporates features of both random and stratified sampling. A weight is associated with each sampled element for the estimation of integrals. It is easier to implement than stratified sampling, yet achieves a good coverage of the sample space of the selected elements [41],[42].

${ }^{6}$ Due to the high level of uncertainty on the properties of the internal furnishing, a fixed relative range of 50\% was selected as appropriate to represent the likely variation on the level of interior thermal mass.
} 
used in the UA are summarised in Table A.3 in the Appendix. A total number of 250 simulations were performed in JEPlus [46], varying multiple parameters concurrently.

To determine the sensitivity of each of the three wall construction methods to physical uncertainties (including the thermal mass of the wall), global sensitivity analysis (SA) was adopted. Physical uncertainties refer to the physical properties of the wall materials; thickness (d), thermal conductivity $(\lambda)$, density $(\rho)$, specific heat capacity (c). Morris's method was employed to generate sampled variables desirable for the SA [47], using again SimLab 2.2.1 [44]. All physical properties under investigation were assigned a mean $(\mu)$ based on the actual construction details from the building case study and a uniform distribution with a fixed relative range of $20 \%$. Details on the mean, minimum and maximum values and used in the SA are summarised in Table A.4 in the Appendix. A total of 630 simulations were performed in JEPlus [46].

As a final step, and in order to gain a better understanding of the transient thermal performance of the ICF wall and how it compares to the other two construction methods (LTM and HTM) with regards to its thermal mass, internal surface temperatures and heat fluxes were plotted based on both measured data from the building and simulation predictions from the models. Intra-fabric temperatures and heat fluxes calculated from the finite difference algorithm employed in EnergyPlus [32] were used to establish whether the thermal storage capacity of ICF concrete core made any contribution to the overall thermal performance of the building.

\section{Results and Analysis}

The results section is structured in four sub-sections. Sub-section 3.1 focuses on the empirical validation of simulation predictions. Sub-sections 3.2 to 3.4 relate to the comparative analysis of ICF to the alternative wall constructions (i.e. HTM and LTM).

\subsection{Validation of simulation models}

The monitoring results in terms of zone mean air temperature for both periods of analysis (i.e. summer and spring weeks) were plotted against the simulation predictions provided by the BPS model. There was good agreement between simulation and measured data for both periods (Fig.2 and 3). During summer (Fig. 2) the error between monitoring and simulation results was calculated to $\mathrm{RMSE}=0.25^{\circ} \mathrm{C}$. The Mean Biased Error showed that the simulation model tends to under-predict the zone mean air temperature by $\mathrm{MBE}=0.02 \%$. In cold weather (Fig.3), the error between simulation predictions and the actual zone mean air temperature was calculated as $\mathrm{RMSE}=0.45^{\circ} \mathrm{C}$. The $\mathrm{MBE}$ indicated that the simulation model again under-predicts the internal air temperatures for the week under investigation by $\mathrm{MBE}=1.05 \%$. To date, there is no standard methodology available to calibrate a model in terms of indoor air temperatures. The 

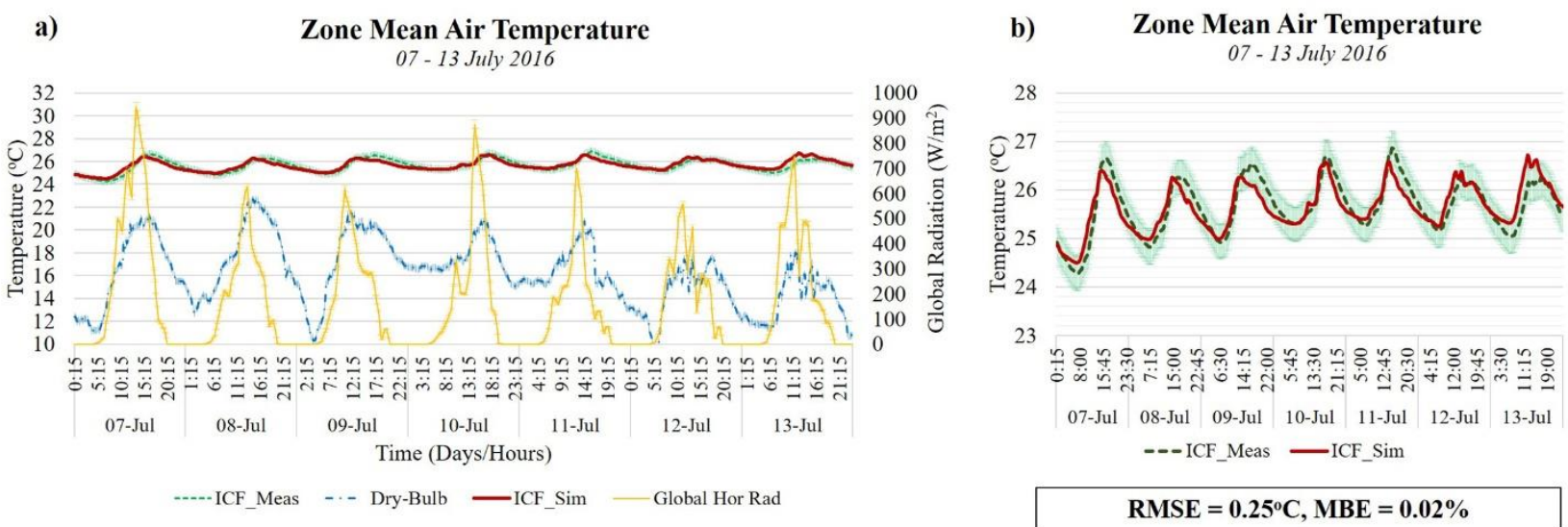

Figure 2: Empirical Validation of ICF simulation results. a) Monitoring results on zone mean air temperature, drybulb temperature and global radiation, $b$ ) closer view of comparison between monitoring results and simulation predictions. Warm period analysis for the unoccupied week $07-13 / 07 / 16$. The green area in the graphs indicates the measurement uncertainty of the internal air monitoring sensors.
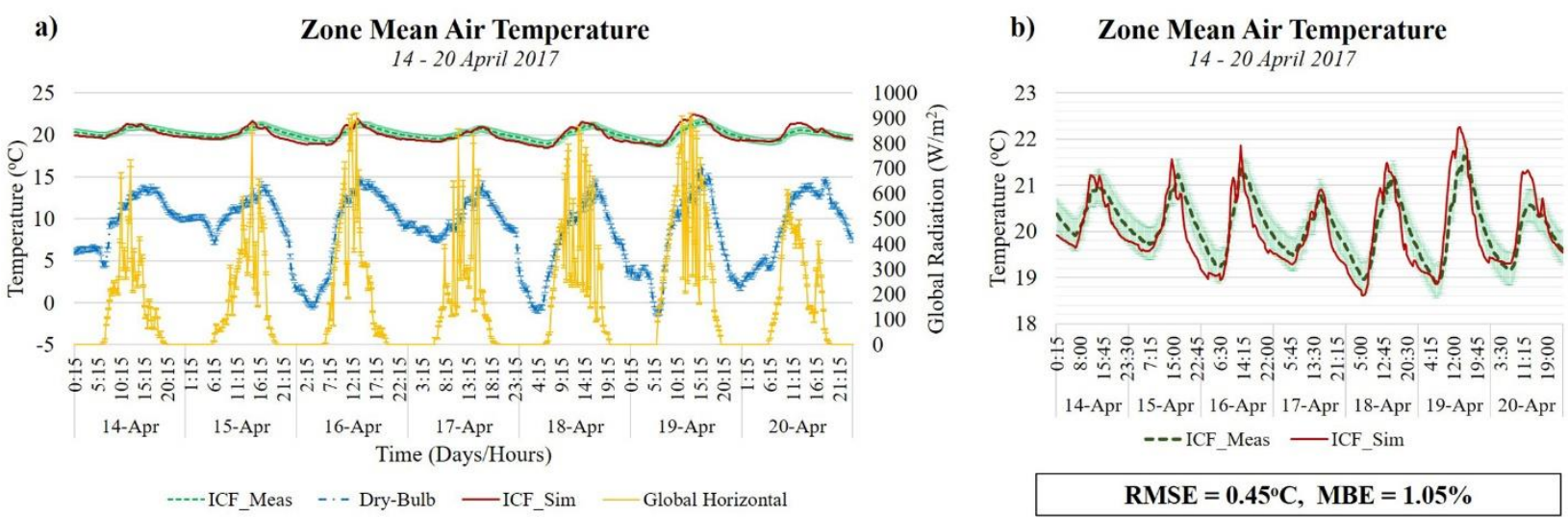

Figure 3: Empirical Validation of ICF simulation results. a) Monitoring results on zone mean air temperature, drybulb temperature and global radiation, $b$ ) closer view of comparison between monitoring results and simulation predictions. Cold period analysis for the unoccupied week $14-20 / 04 / 17$. The green area in the graphs indicates the measurement uncertainty of the internal air monitoring sensors.

Looking at the dynamic characteristics of the building fabric (i.e. decrement delay $\omega$ and decrement factor $\mathrm{D}_{\mathrm{f}}$ ) for the summer period (Fig.4), it becomes apparent that although there is a very good consistency between measured results and simulation predictions for the decrement factor $D_{f}$ (the percentage difference between average measured $D_{f}$ and the average simulated $\mathrm{D}_{\mathrm{f}}$ is c. $2 \%$ ), the model tends to under-predict the decrement delay $\omega$ (62\% lower $\omega$ is estimated by the model compared to reality). A better agreement is observed in the prediction of the decrement delay during spring 
period $^{7}$ as shown in Fig.5a, yet once again the model under-predicts the decrement delay in comparison to the actual performance of the building (c.33\% lower $\omega$ is calculated based on simulation predictions when compared to measured data). Furthermore, during spring period, the model over-predicts the average value of the decrement factor, in comparison to reality, by c.40\% (Fig.5b).

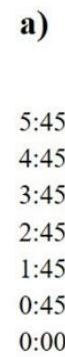

a)

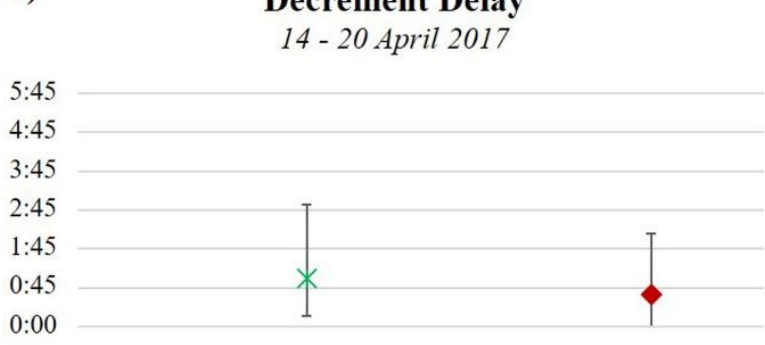

$\omega \_$Meas
Decrement Delay

07 - 13 July 2016

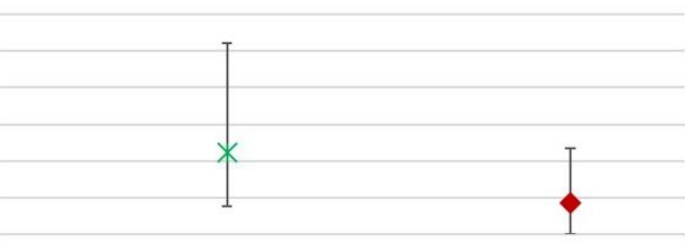

$\omega \_$Meas $\omega \_\operatorname{Sim}$

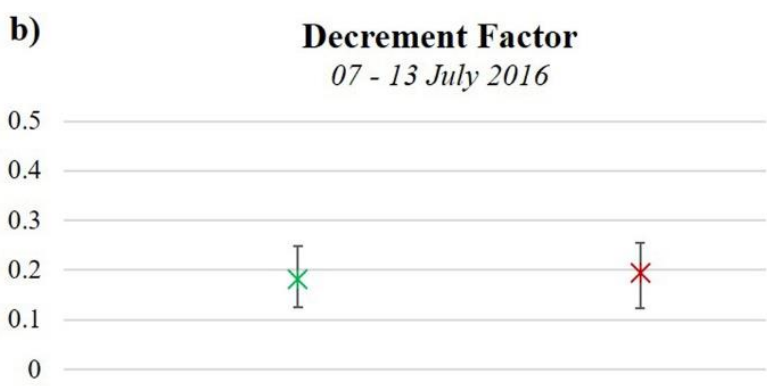

Df_Meas

Df_Sim

Figure 4: Dynamic characteristics of the ICF fabric, as calculated based on monitoring results and simulation predictions for the summer unoccupied week 07 - 13/07/16; a) Decrement Delay, b) Decrement Factor predictions for the spring unoccupied week 14 - 20/04/17; a) Decrement Delay, b) Decrement Factor

\subsection{The impact of varying thermal mass on zone mean air temperature}

\subsubsection{The thermal mass of external wall construction}

The zone mean air temperature of the ICF building was compared against the HTM and the LTM building, for the summer week, 07 - 13 July 2016 (Fig.6). The graphs shows that the ICF building sits between the other two construction methods and behaves more similarly to the HTM building. The diurnal temperature variation of ICF increased slightly compared to the HTM building, with higher peaks of maximum air temperature. The diurnal profile of the LTM building

\footnotetext{
${ }^{7}$ No time lag was evident in the measured data between the time of the maximum ambient and the maximum internal air temperature for the cold period. As a result, the decrement delay for spring was calculated based on the time lag between the minimum ambient temperature and the minimum internal air temperature.
} 
was similar to the other two construction methods, yet the internal air temperature in the LTM building was higher, by an average of $2^{\circ} \mathrm{C}$

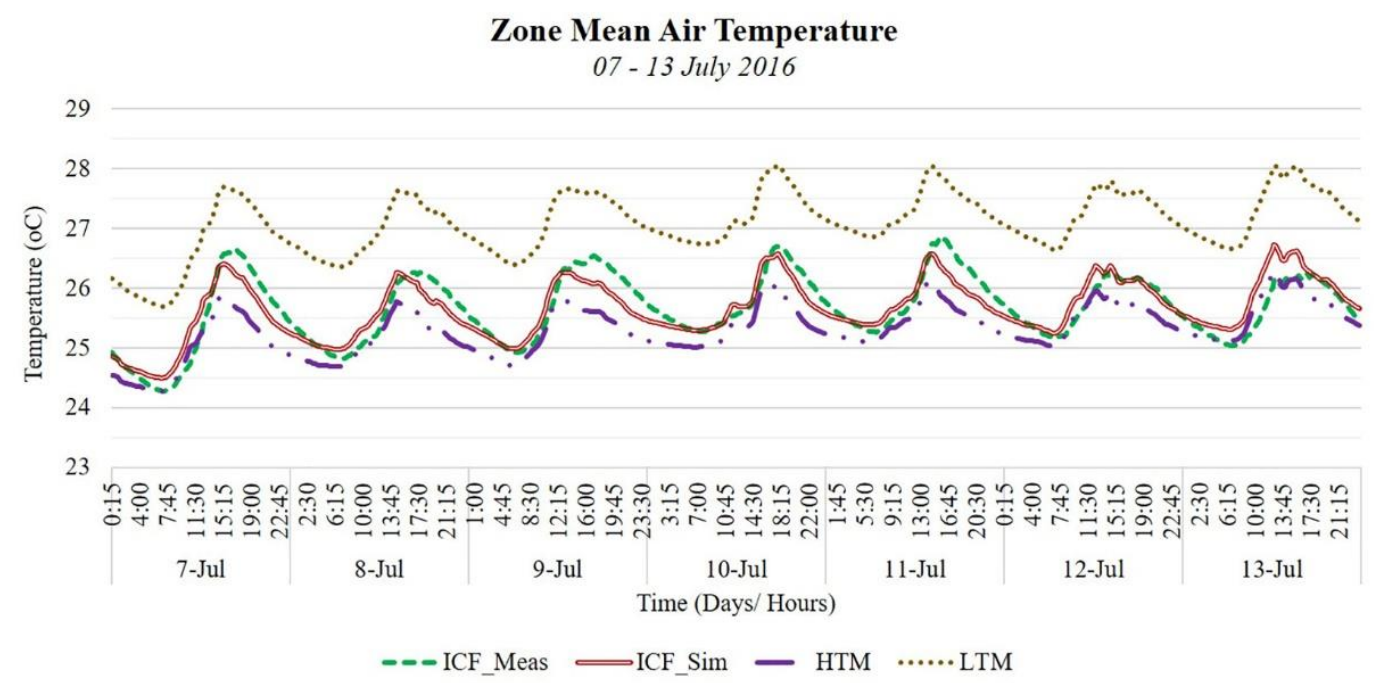

Figure 6: Comparison of zone mean air temperatures between the three different construction methods for the summer unoccupied week 7 - 13 July 2016. Simulation results for the ICF, HTM and LTM buildings plotted against measured data for the ICF building.

The daily temperature profile for all three building cases was plotted for a representative day in the summer week (Fig.7). The figure compares: the expected performance of the thermal mass based on theory (Fig.7a), the simulation results provided by the three models (Fig.7b), and the comparison between simulation and monitoring results for the ICF building (Fig.7c). One would expect the diurnal temperature fluctuation of the LTM building to be higher than the other two construction methods and closer to the ambient temperature profile (Fig.7a), due to the anticipated quick response of the low thermal mass fabric to changes in boundary conditions. However, based on the simulation results provided by the three models (Fig. 6 and 7b), the LTM building showed a similar dampening effect on the internal air temperature to the other two buildings. This can be attributed in part to the heavyweight ground floor, which was the same in all three models. The comparison between monitoring and simulation results, for the summer representative day (Fig. 7c), highlighted what was discussed earlier (Fig.2 and 4), i.e. that the simulation model was able to predict correctly the amplitude of the diurnal temperature wave, yet it under-predicted the decrement delay between the maximum internal and external air temperature. A finding which also applies to the other two construction methods (Fig. 7b). 

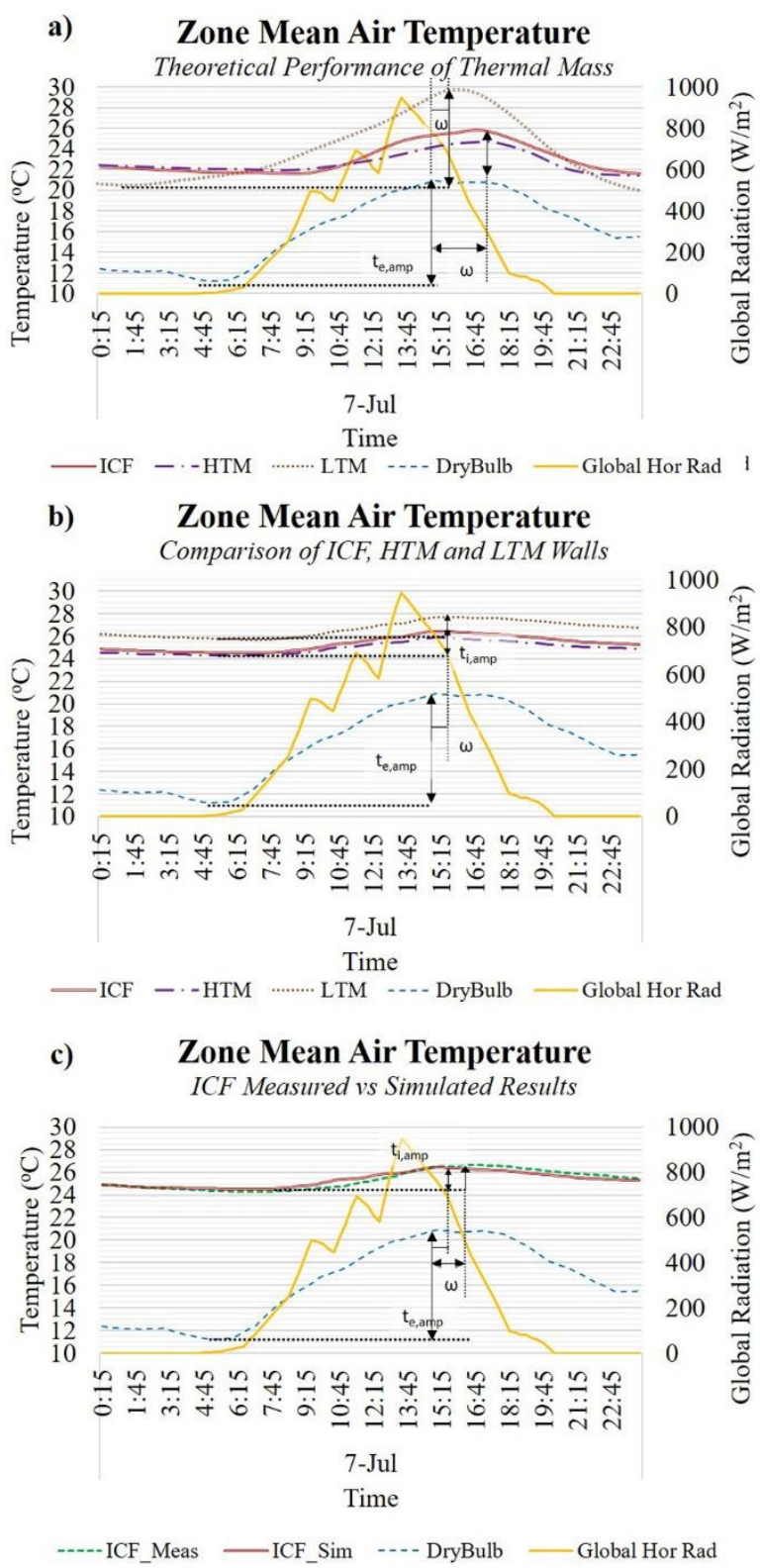

Figure 7: Calculation of decrement factor and decrement delay of the three construction methods, ICF, HTM and LTM. Results plotted for a typical day in the summer unoccupied period. Comparison of: a) theoretical (expected) performance of thermal mass, $b$ ) simulation results for the three wall constructions, $c$ ) measured and simulation results for the ICF fabric.

The daily decrement factor as calculated for the three buildings cases, based on the simulation predictions, was compared to the actual Df of the building, as calculated from the monitoring results (Fig.8). The graph shows that for the ICF building the simulation tends to slightly under-predict the decrement factor during warm weather, in comparison to the monitoring performance by RMSE $=0.04$ (with an MBE $=-2.15 \%$ ). Based on simulation, the ICF and the LTM building had almost the same decrement factor $D_{f}$ during the summer week, ranging between $D_{f}=0.15$ and $D_{f}=0.25$. The $H T M$ building showed a lower decrement factor, compared to the other two buildings, fluctuating between $D_{f}=0.10$ and $D_{f}=$ 0.21 . 


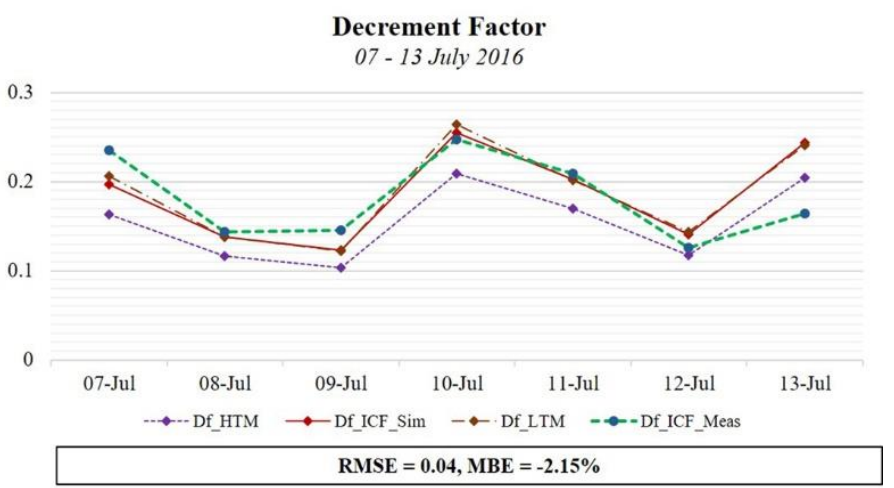

Figure 8: Comparison of decrement factor for the three construction methods, ICF, HTM and LTM as calculated based on the monitoring results and simulation predictions for the summer unoccupied week 07 - 13 July 2016.

The daily temperature variation of the ICF building was compared to the other two construction methods, for the spring cold week (Fig.9). Here, the daily temperature profiles are closer in all three models than it was in summer (Fig. 7). The LTM building showed a slightly increased internal air temperature compared to the other two buildings. The difference between ICF and the HTM buildings was insignificant.

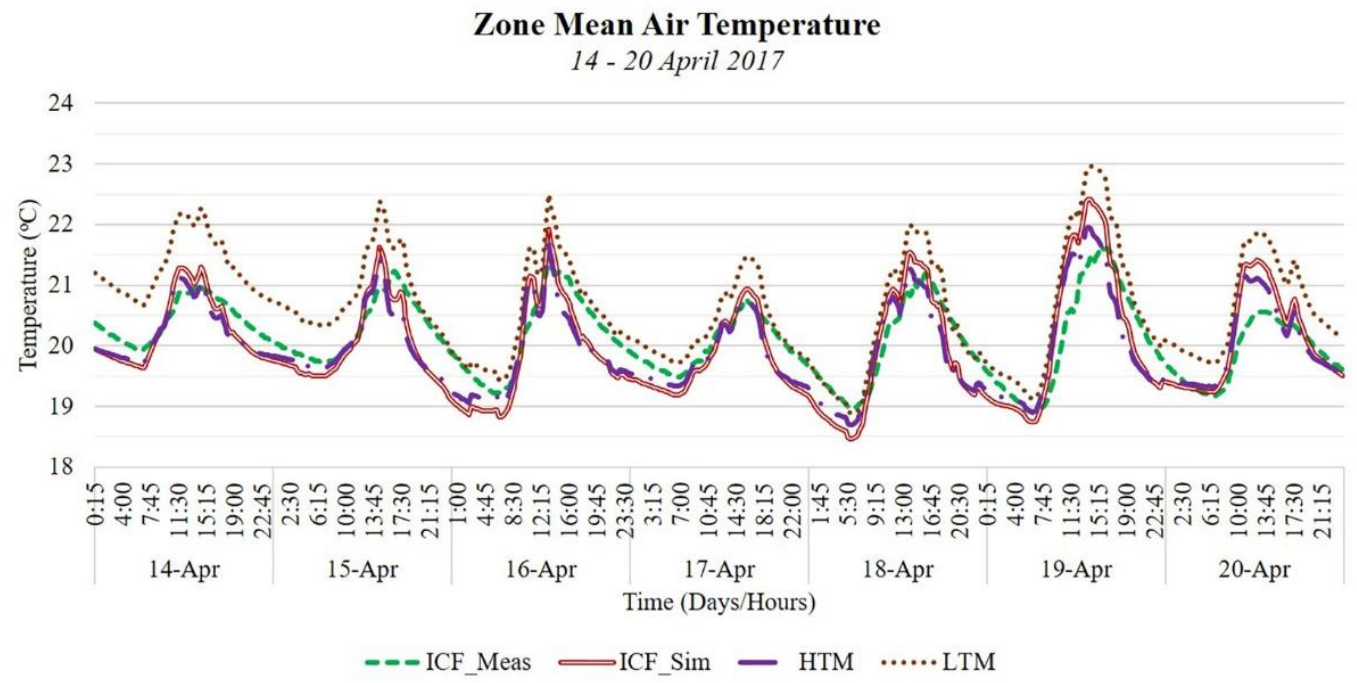

Figure 9: Comparison of zone mean air temperatures between the three different construction methods for the spring unoccupied week, 14 - 20 April 2017. Simulation results for the ICF, HTM and LTM buildings plotted against measured data for the ICF building.

The decrement factor as calculated for the three different buildings cases, based on the simulation predictions, as opposed to monitoring results is illustrated in Fig.10 for the cold week in April. Here, the simulation model of the ICF building over-predicts the decrement factor of the fabric in comparison to the actual Df calculated from monitoring data by RMSE $=0.1$ (with an $\mathrm{MBE}=40 \%$ ). Based on the simulation predictions, the ICF and the LTM building had again almost the same decrement factor and the same range of variation throughout the week (i.e. between $\mathrm{D}_{\mathrm{f}}=0.18$ and $\mathrm{D}_{\mathrm{f}}=0.3$ ). The 
HTM building showed a lower average Df compared to the other two construction methods, and a smaller range of variation (between $\mathrm{D}_{\mathrm{f}}=0.15$ and $\mathrm{D}_{\mathrm{f}}=0.23$ ).

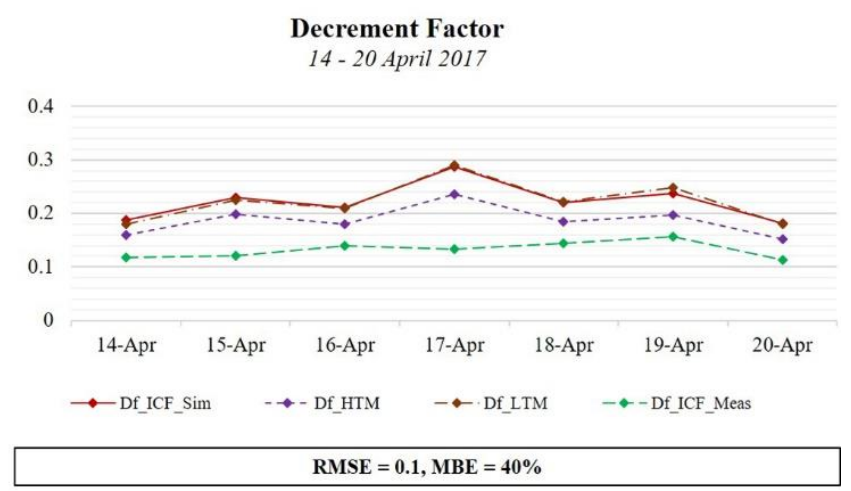

Figure 10: Comparison of decrement factor for the three construction methods, ICF, HTM and LTM as calculated based on the monitoring results and simulation predictions for the spring unoccupied week 14-20 April 2017.

\subsubsection{Contribution of ground floor's thermal mass}

To investigate the contribution of ground floor's thermal mass in the thermal inertia of the whole building, the LTM building was simulated with a lightweight floor construction, the HTM building was simulated as it was (i.e. with heavyweight ground floor) and the ICF building was simulated with three different floor constructions, varying the level of thermal mass from lightweight to medium and heavyweight. The results are illustrated in Fig.11 and confirm what was discussed earlier (Fig.6, 7 and 9). The LTM building had previously shown the same dampening effect in the internal air temperature to the other two building (Fig.6 and 7b) due to the high thermal mass of the floor. When the building was simulated with lightweight ground floor, its diurnal temperature variation was significantly increased during warm and cold periods. The performance of the ICF building was different according to the level of thermal mass in the ground floor. Its diurnal temperature variation, although similar to the HTM building when simulated with heavyweight floor construction, it significantly increased as the level of thermal mass in the floor was decreasing. In fact, when the ICF building was simulated with lightweight floor in the spring unoccupied period, it showed a similar diurnal temperature profile to the LTM building. Nevertheless, during summer, the thermal storage capacity of the ICF walls, even when the ground floor construction was simulated as lightweight, resulted in an average of $2^{\circ} \mathrm{C}$ reduction in the internal air temperatures. 

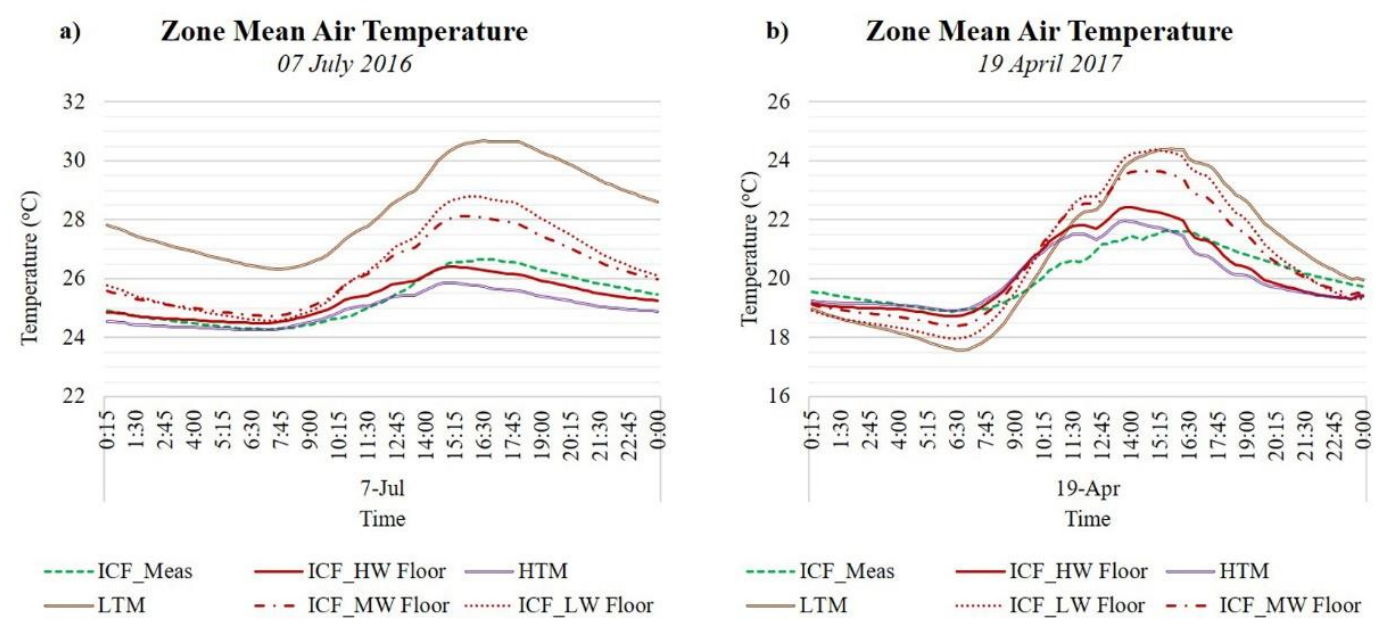

Figure 11: Comparison of ICF zone mean air temperature when varying the thermal mass of the ground floor from lightweight to medium and heavyweight construction. Results plotted against measured data from the ICF monitoring project and simulation predictions for a lightweight floor construction in the LTM building and a heavyweight floor construction in the HTM building. a) summer unoccupied week, 07 -13/07/16, b) spring unoccupied week, 14 20/04/17.

\subsubsection{The impact of interior thermal mass}

The interior thermal mass was simulated in the models based on the material properties of the internal furnishing (from information found in literature [45]) and the surface area of the furniture as measured in the actual building. However, the level of uncertainty in the input values remains high. In order to assess the role of interior thermal mass in the simulation results divergence, a global uncertainty analysis (UA) was performed. The results of the UA (Fig.12) indicated that the range of variation in the simulation of the zone maximum air temperature due to uncertainties in the interior thermal mass properties was small and equal to $0.47^{\circ} \mathrm{C}$ during warm period. During cold period the uncertainty in the zone maximum air temperature due to internal furnishing was insignificant.

a) Zone Maximum Air Temperature Impact of Internal Thermal Mass $07-13$ July 2016

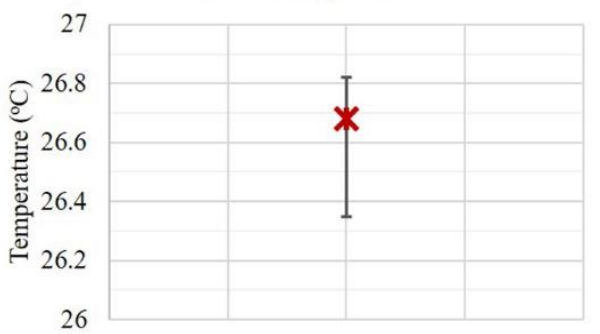

b) Zone Maximum Air Temperature Impact of Internal Thermal Mass $14-20$ April 2017

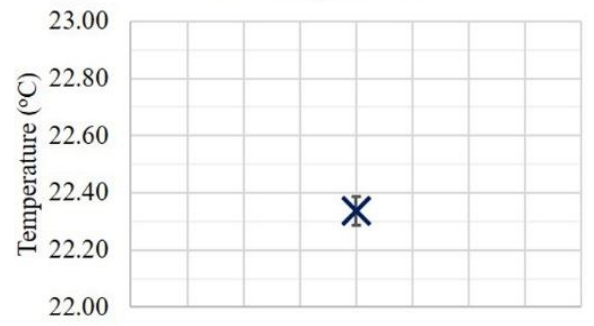

Figure 12: Variation of zone maximum air temperature due to uncertain input values in the interior thermal mass due to furnishing: a) summer unoccupied week, 07 - 13/07/16, b) spring unoccupied week, 14 - 20/04/17. 


\subsection{Sensitivity analysis of wall material properties}

The results of the sensitivity analysis are shown in Fig 13 for all three construction methods, for the summer unoccupied week and in Fig.14 for the spring unoccupied week. The bar charts in Fig.13 and 14 show the ranking order of the input parameters, in other words the overall influence of each input factor on the simulation output [47],[50]. The $\mu^{*}$ is an absolute value, and although it is considered as a good indication of the absolute importance of the input factor, it does not give any insight on the whether the input parameters have an influence on the results with a positive or negative sign. A graphical representation of $\sigma$ vs $\mu^{*}$ (given in the scatter graphs of Fig.13 and 14) is given to evaluate the monotonicity of the input parameters. If the input factors are positioned below $\sigma / \mu^{*}=0.1$ line then their behaviour is considered linear. If the input factors are positioned between the lines $\sigma / \mu^{*}=0.1$ and $\sigma / \mu^{*}=0.5$ then they are monotonic. If the input factors are between the lines $\sigma / \mu^{*}=0.5$ and $\sigma / \mu^{*}=1$ they are almost-monotonic. Finally, if they are above the $\sigma / \mu^{*}=1$ line they are considered highly non-linear and non-monotonic [50],[51].

The SA results showed that during the summer period (Fig. 13) the most significant parameters influencing the zone mean air temperature for the ICF building were the density, specific heat capacity and thickness of the concrete core, followed closely by the conductivity and thickness of the internal insulation layer, and the conductivity of the external insulation layer. In other words, the most important parameters affecting the internal air temperature of an ICF building during summer was the thermal mass of the concrete core and the thickness and conductivity of the internal insulation. Similar findings apply to the HTM building. The properties of the concrete (i.e. thickness, specific heat capacity and density) showed the most significant effect on the internal air temperature. The other two parameters that affected the zone mean air temperatures were the thickness and conductivity of the insulation layer.

During the unoccupied week in April the results of the sensitivity analysis (Fig. 14) showed that for the ICF building, similarly to summer (Fig. 13), the zone mean air temperature was mostly affected by the properties of the concrete core (i.e. density, thickness, specific heat capacity,). Moreover, other influential parameters were found to be the conductivity of the layers of insulation both internally and externally. The external insulation layer, which was found to have an insignificant effect on the zone mean air temperature during summer, was found to be among the most sensitive parameters affecting the internal environment during cold weather. In the spring unoccupied week, the internal air temperature of the HTM building, in contrast to summer, was mostly sensitive to conductivity and thickness of the insulation layer, followed by thermal mass of the concrete layer (thickness, specific heat capacity and). In the LTM building, where there is no heavyweight layer in the construction of the wall, the zone mean air temperature was mostly sensitive to the thickness and conductivity of the insulation during both warm and cold periods. 

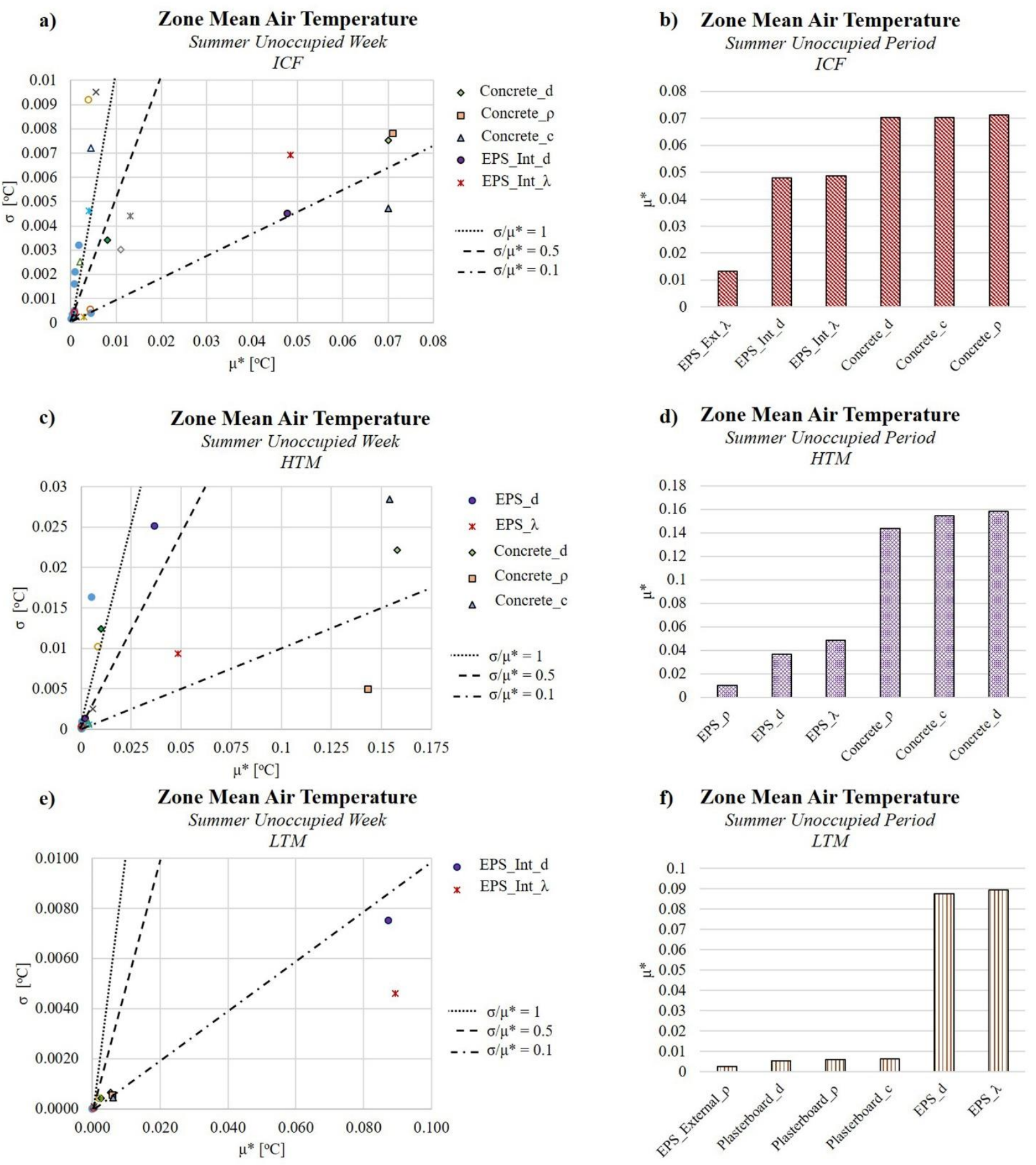

\section{f) Zone Mean Air Temperature} Summer Unoccupied Period LTM

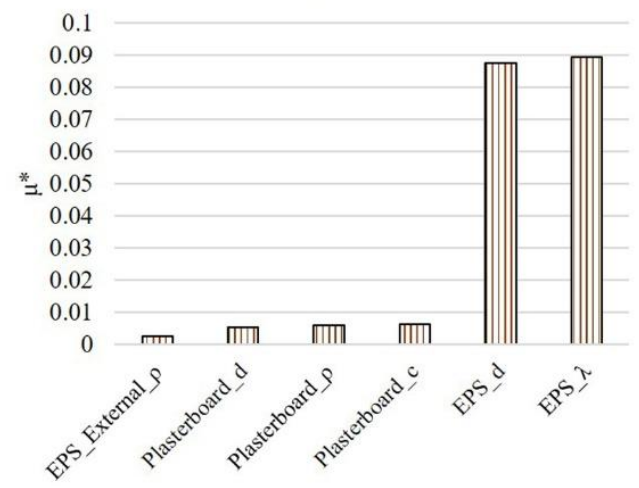

Figure 13: Morris analysis of absolute mean $\left(\mu^{*}\right)$ and standard deviation $(\sigma)$ on mean zone air temperature when considering uncertainty in external wall material properties during summer unoccupied week: a) ICF Morris plot, $b$ ) ICF sensitivity ranking, c) HTM Morris plot, d) HTM sensitivity ranking, e) LTM Morris plot, f) LTM sensitivity ranking. 

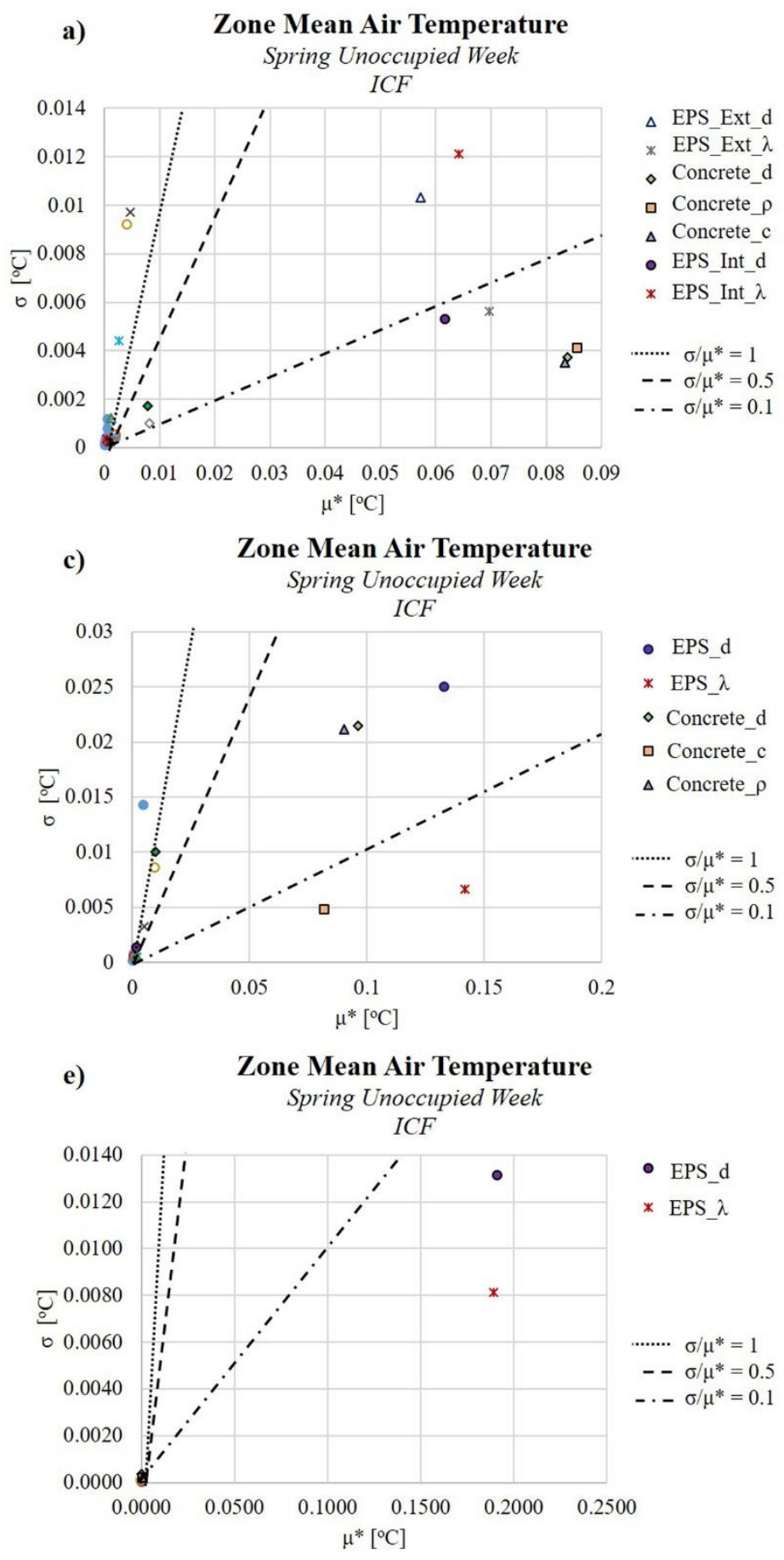

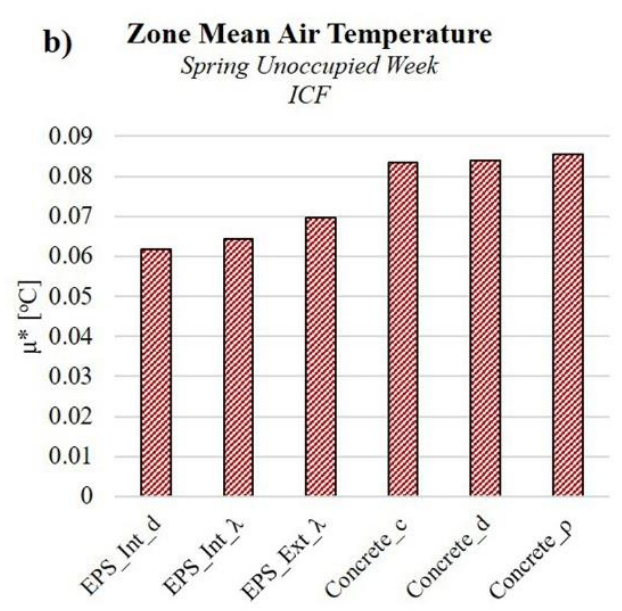
d) Zone Mean Air Temperature Spring Unoccupied Period $I C F$

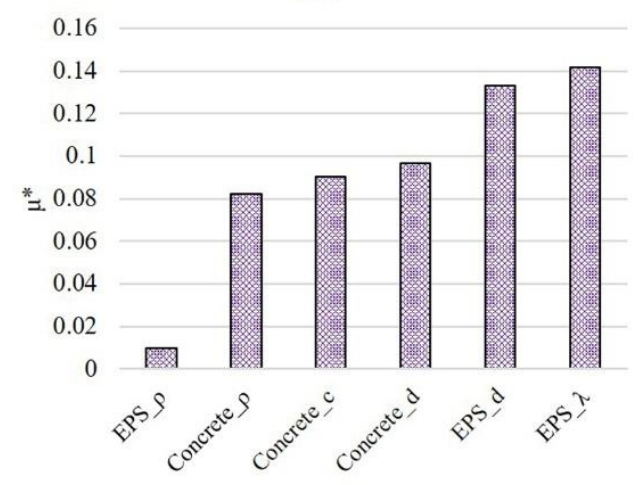

f) Zone Mean Air Temperature Spring Unoccupied Period $I C F$

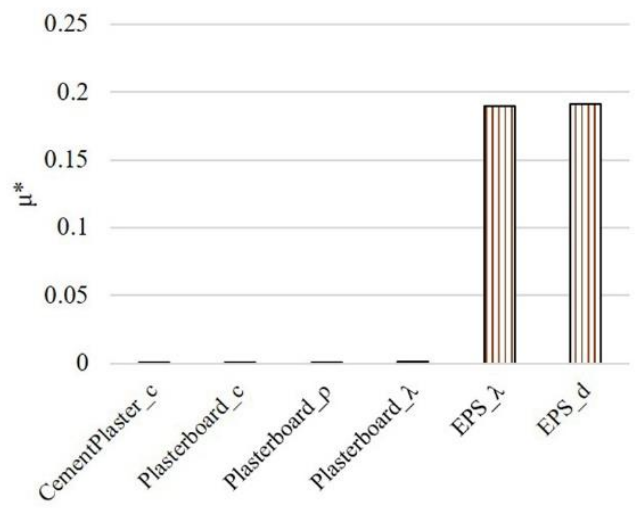

Figure 14: Morris analysis of absolute mean $\left(\mu^{*}\right)$ and standard deviation $(\sigma)$ on mean zone air temperature when considering uncertainty in external wall material properties during spring unoccupied week: a) ICF Morris plot, b) ICF sensitivity ranking, c) HTM Morris plot, d) HTM sensitivity ranking, e) LTM Morris plot, f) LTM sensitivity ranking.

\subsection{The impact of thermal mass on internal face heat flux}

The results of the sensitivity analysis for the two analysed periods indicated that the thermal storage capacity of the ICF concrete core affects internal air temperatures. In the following section, to investigate this issue further, the transient 
performance of the three wall construction methods was investigated by analysing the internal surface and intra-fabric temperature and the internal surface conduction heat flow rate and energy.

Measured data for the inside wall surface heat flux were plotted in comparison to the inside surface, the intra-fabric and the zone air temperature for a three-day period in the warm summer weather (Fig.15a) and three days in the cold spring week (Fig.15b). During warm weather the temperature of the concrete core was relatively steady $-\operatorname{around} 24^{\circ} \mathrm{C}$. The surface and zone air temperature fluctuated between $24.5^{\circ} \mathrm{C}$ and $26^{\circ} \mathrm{C}$. The $\Delta \mathrm{t}$ between the inside wall surface and the concrete core temperature was always higher than the $\Delta \mathrm{t}$ between the surface and the zone mean air temperature. Throughout the three days under investigation the heat flow was consistently from the inside of the zone towards the interior of the fabric (constant heat loss to the exterior, indicated with negative sign). There was no evidence of reversed heat flow (i.e. heat dissemination from the wall to the space).

During the cold spring period, the monitoring results of the inside surface heat flux indicate a slightly increased heat flow rate (Fig. 15b) in comparison to the summer period (Fig.15a). Similarly to summer, the heat flow was consistently from the inside space towards the inside of the fabric. The wall surface showed slightly increased peaks of maximum in comparison to the zone mean air temperature. The monitored concrete core temperature was again relatively constant and around $17.5^{\circ} \mathrm{C}$. The $\Delta \mathrm{t}$ of the surface temperature to the intra-fabric temperature was always higher for the whole three-day period compared with the $\Delta \mathrm{t}$ of the surface temperature and the zone air temperature. As a result, the heat flow was always from the internal space towards the exterior (negative sign), and there was no evidence of heat gains from the wall to the space.

a) Inside Face Surface Temperature and Heat Flux

Summer Unoccupied Period ICF Measured Data

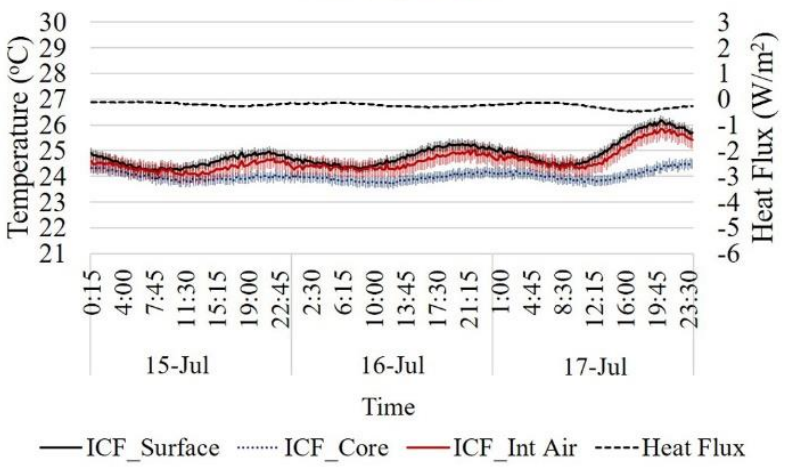

b) Inside Face Surface Temperature and Heat Flux

Spring Unoccupied Period ICF Measured Data

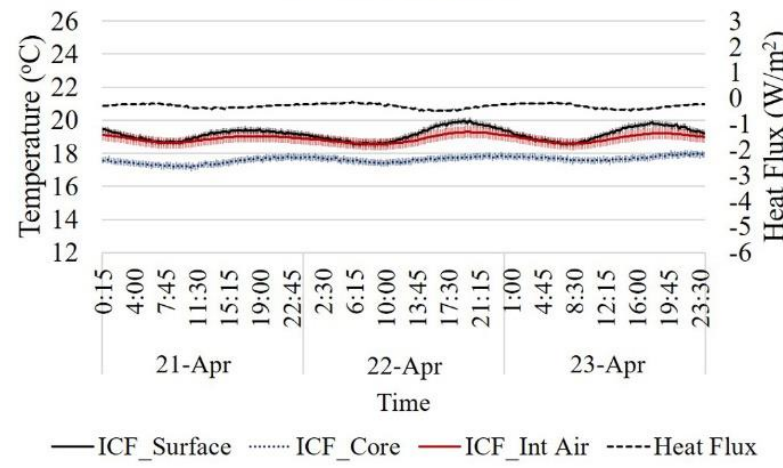

Figure 15: ICF measured inside surface, intra-fabric and internal air temperature plotted in comparison to inside face heat flux: a) three representative days of the summer unoccupied period, 15-17 July 2016, b) three representative days of the spring unoccupied period 21-23 April 2017. 
The simulation results provided by the three models for the inside wall surface heat flux, the inside surface, intra-fabric and the zone mean air temperature were plotted for the ICF building (Fig.16a), the HTM building (Fig,16b) and the LTM building (Fig.16c) for the cold period. Similar observations were found for both weeks (i.e. warm and cold weather), however for sake of brevity only the results of the cold period are presented here.

The comparison of monitoring results (Fig. 15b) to simulation predictions for the ICF building (Fig. 16a) show that the model tends to under-estimate the intra-fabric temperature, by approximately $1^{\circ} \mathrm{C}$. This resulted in a slightly increased heat flux, compared to the actual monitored performance of the ICF wall. Moreover, the simulation model underestimated the surface temperature in some instances and predicted a slightly higher daily temperature variation (reaching up to $2^{\circ} \mathrm{C}$ ), when the monitoring results showed a maximum diurnal temperature variation of $1^{\circ} \mathrm{C}$. In the comparison of the ICF building to the HTM and the LTM building (Fig.16), the ICF building showed the lowest heat flux of all three cases with a consistent heat flow from the interior of the space towards the inside of the fabric (similar to the monitoring performance - Fig. 15b). The HTM and the LTM buildings showed evidence of heat being disseminated from the wall to the internal space. In the HTM building (Fig.16b) the wall surface and intra-fabric temperature were almost the same with very little variation during the three days analysed. The zone mean air temperature fluctuated in a smaller range compared to the other two buildings. The heat flow was mostly from the internal space towards the fabric from midday until midnight. Some of this heat was released back into the space from midnight until the middle of the following day; showing evidence of the ability of the thermal mass to capture and store internal heat gains. The LTM building showed increased heat flow rates compared to the ICF building, with some instances of heat flowing from the outside to the internal space. The ICF and the HTM buildings showed a relatively stable intra-fabric temperature, around $16^{\circ} \mathrm{C}$ and $18^{\circ} \mathrm{C}$, respectively. In the LTM wall, the intra-fabric temperature fluctuated in a range of $12^{\circ} \mathrm{C}$, between $13^{\circ} \mathrm{C}$ and $25^{\circ} \mathrm{C}$. 

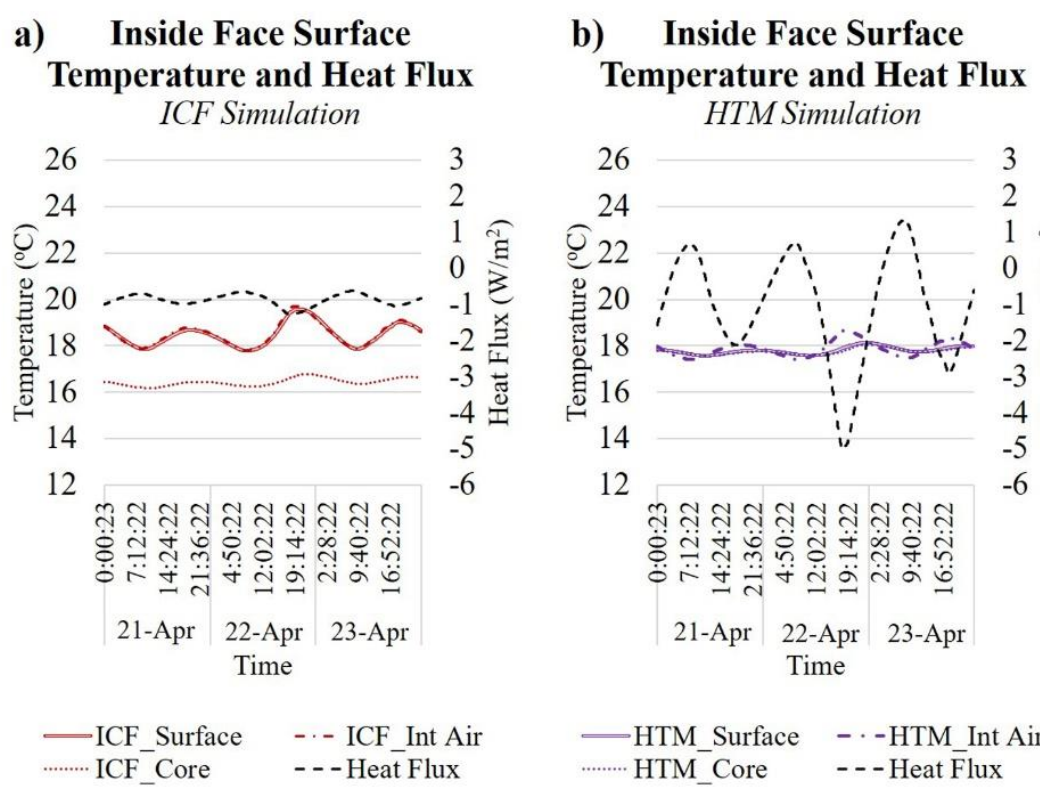

\section{c) Inside Face Surface Temperature and Heat Flux}
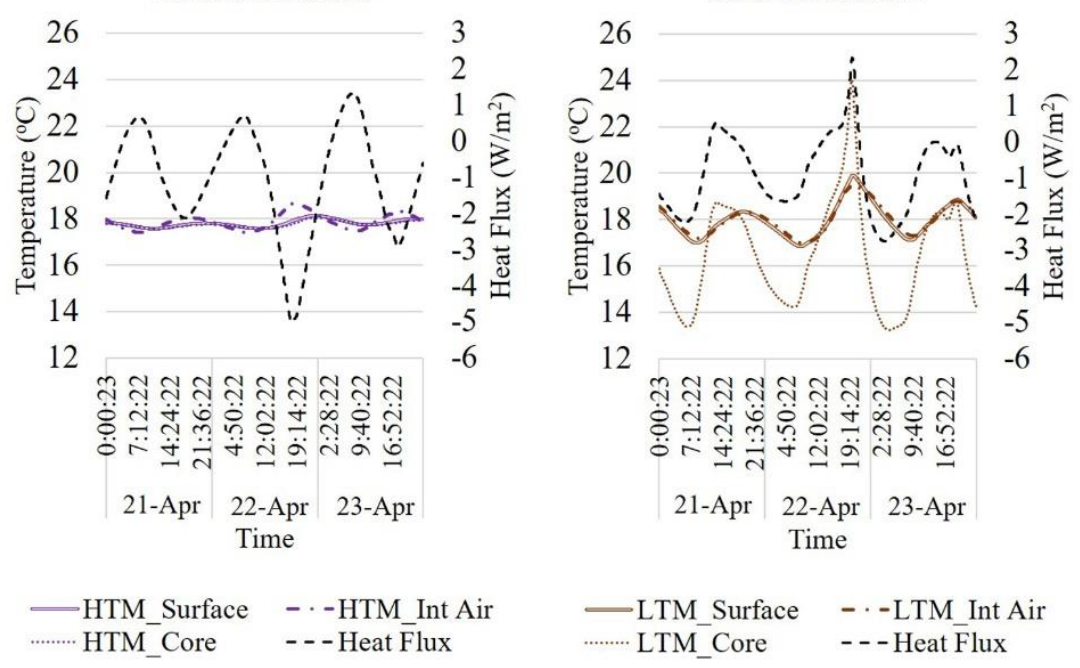

Figure 16: Simulated inside surface, intra-fabric and internal air temperature plotted in comparison to inside face heat flux for three representative days of the cold unoccupied week, 21 - 23 April 2017: a) ICF wall, b) HTM wall, c) LTM wall.

The intra-fabric temperature gradient of the three wall constructions was plotted in four time-steps during the course of a cold day (Fig.17). The temperature of the ICF concrete core was stable and around $16^{\circ} \mathrm{C}$ (Fig. $17 \mathrm{a}$ ). The inside wall surface temperature fluctuated by $1.5^{\circ} \mathrm{C}$ (between $17.5^{\circ} \mathrm{C}$ and $19^{\circ} \mathrm{C}$ ), while the outside surface temperature showed significant daily variations in the range of $20^{\circ} \mathrm{C}$ (between $2{ }^{\circ} \mathrm{C}$ and $22^{\circ} \mathrm{C}$ ). Similar observations apply to the HTM building (Fig.17b). In the LTM building (Fig.17c), the outside surface temperature fluctuated in the same range as the other two construction methods (i.e. between $2^{\circ} \mathrm{C}$ and $22^{\circ} \mathrm{C}$ ). However, the inside surface and intra-fabric temperature variation was significantly increased compared to the other two walls. More specifically, the inside surface showed a daily fluctuation between $15.5^{\circ} \mathrm{C}$ and $18.5^{\circ} \mathrm{C}$ and the intra-fabric temperature variation was in the range of $7.5^{\circ} \mathrm{C}$ (between $10^{\circ} \mathrm{C}$ and $17.5^{\circ} \mathrm{C}$ ). The corresponding internal air temperature variation was plotted for the same cold day analysed (i.e. $23^{\text {rd }}$ of April 2017) for all three constructions, ICF (Fig.18a), HTM (Fig.18b) and LTM (Fig.18c). The graphs show that, as anticipated, the HTM building had the smaller diurnal internal air temperature variation, $\Delta \mathrm{t}=0.7^{\circ} \mathrm{C}$. The ICF building showed higher internal air temperatures in comparison to the HTM building (with a range between $18^{\circ} \mathrm{C}$ and $19^{\circ} \mathrm{C}$ ) and a higher diurnal variation $\left(\Delta \mathrm{t}=1^{\circ} \mathrm{C}\right)$. The LTM building showed the highest variation of all three construction methods, $\Delta \mathrm{t}=1.5^{\circ} \mathrm{C}$, and its internal air temperature being in the range between $17.5^{\circ} \mathrm{C}$ and $19^{\circ} \mathrm{C}$. 
a)

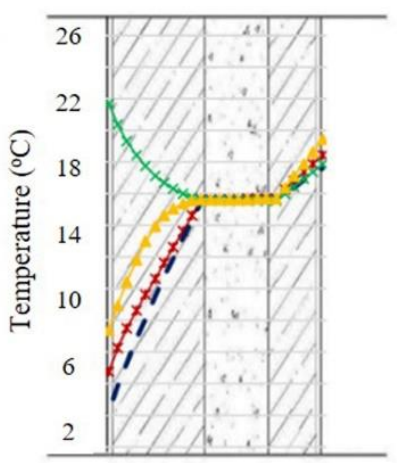

b)
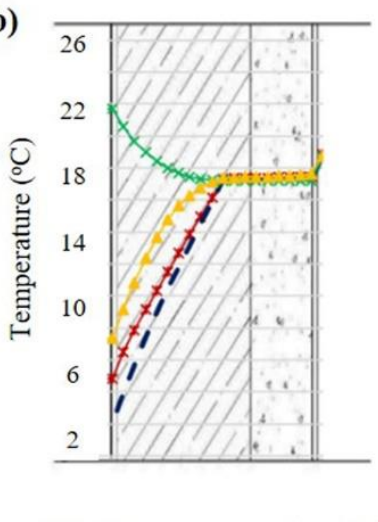

c)

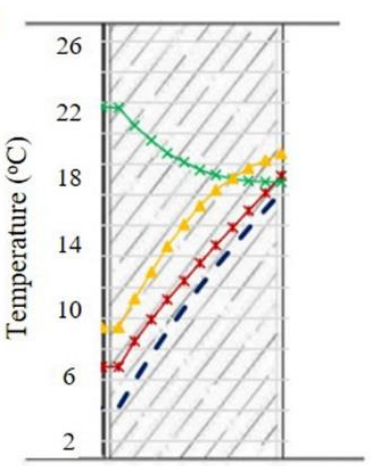

18:00

Figure 17: Simulation results on intra-fabric temperature distribution for a representative day of spring, 23 April 2017: a) ICF, b) HTM, c) LTM.
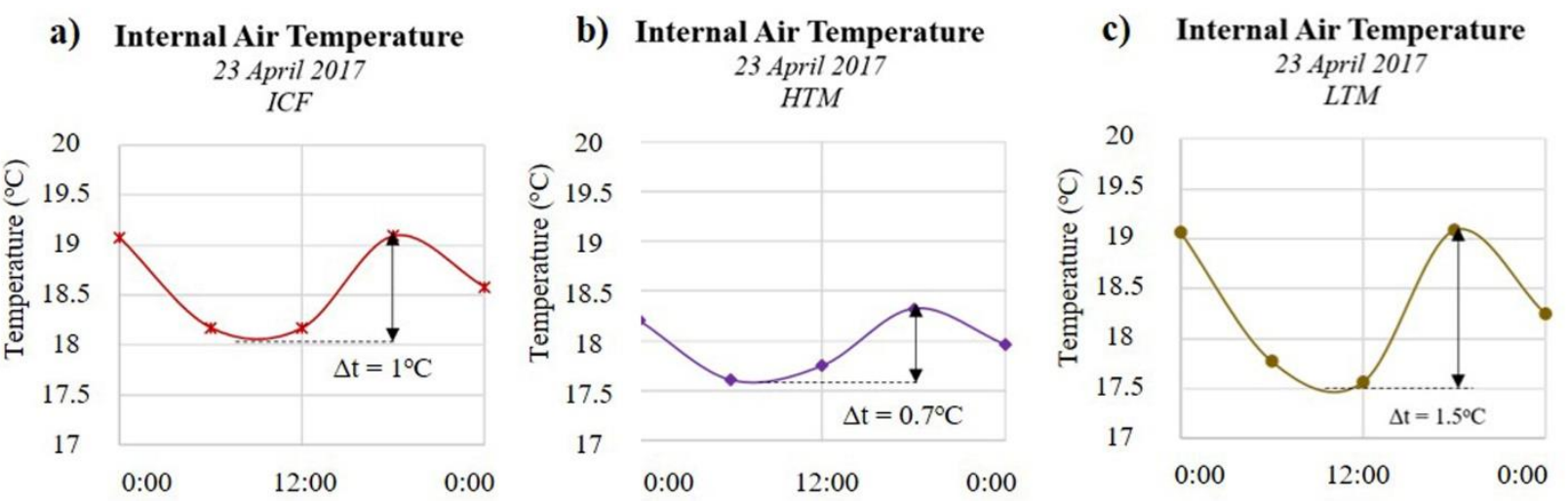

Figure 18: Simulation results on internal air temperature variation for a representative day of spring, 23 April 2017: a) ICF, b) HTM, c) LTM.

The cumulative conduction heat flow energy from the inside wall surface for the ICF and the LTM buildings was plotted for three days during the cold period (Fig.19). The aim was to perform a direct comparison between the LTM and the ICF walls to investigate the impact of the ICF thermal mass on the heat flowing in and out of the building. Since both wall constructions have the same thermal transmittance (U-value), any difference in the total heat losses and gains can be solely attributed to the thermal mass of the ICF concrete core. The total heat loss of the LTM building was calculated to be around $280 \mathrm{Wh}$, whereas the corresponding total heat loss of the ICF building was around $180 \mathrm{Wh}$. The ICF showed $100 \mathrm{Wh}$ less heat loss to the exterior due to the thermal storage capacity (and the constant temperature) of the concrete core. Moreover, the LTM wall showed 30Wh of heat gains from the outside to the interior of the space, when the ICF wall showed no evidence of heat gains. 

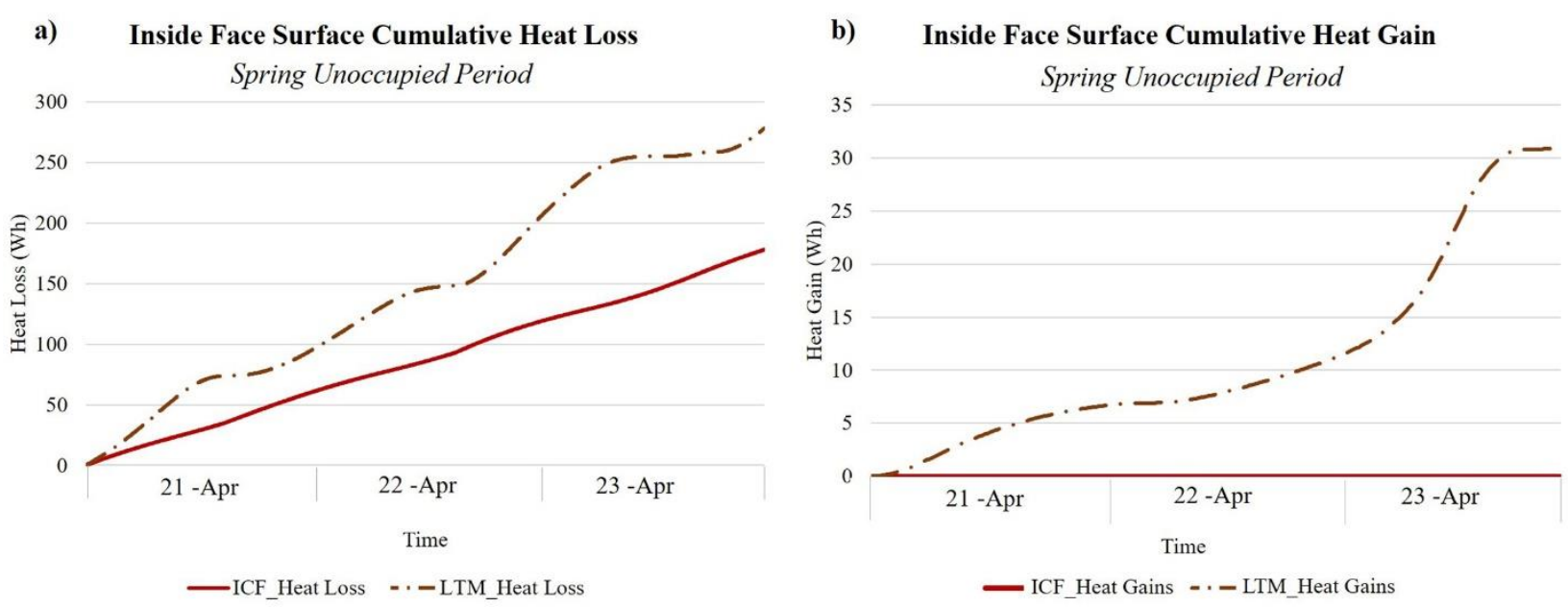

Figure 19: Inside face surface cumulative conductive heat energy flow. Comparison of ICF and LTM walls for three representative days of the spring unoccupied period, 21 - 23 April 2017: a) Conduction heat loss from zone to the exterior, $b$ ) Conduction heat gain for the exterior to zone.

\section{Discussion}

The following section discusses the academic implications of this research, in respect of key literature in the area, and makes clear the contribution to knowledge. Although there is a number of previous studies analysing the thermal performance of ICF, these were mostly either field studies, measuring the performance of specific buildings in specific scenarios [14], or simulation studies, without a means to evaluate the accuracy of simulation predictions [17][18][20]. There are only a few studies that combine monitoring and simulation results, yet these typically focus only on surface temperatures and heat flow rates and were performed for the cold climate of Canada [15][16][19]. To the authors' knowledge that is the first whole building monitoring study which combines computational analysis and empirical data, to investigate the thermal performance of an actual ICF building located in the temperate UK climate. The actual thermal performance of an ICF building is evaluated empirically and the monitoring results are used to build confidence on the accuracy of simulation predictions. Subsequently, "what-if" scenarios of alternative wall constructions are combined to an in-depth computational analysis to draw conclusions on the transient thermal performance of ICF.

\subsection{Empirical validation of simulation results}

The analysis showed that the measured internal temperature of the ICF building is significantly more stable than the external dry-bulb temperature, which showed high diurnal swings. The small diurnal internal air temperature variation throughout both analysed periods confirms that the building fabric has a dampening effect, reducing internal temperature swings to a much smaller range than the ambient temperature, providing a stable internal environment.

The simulation model of the ICF building was able to predict with a relatively good accuracy the amplitude of the internal air temperature daily swings during both summer and spring (RMSE $=0.25^{\circ} \mathrm{C}$ and $\mathrm{RMSE}=0.45^{\circ} \mathrm{C}$, respectively). However, in cold spring period the peaks of the maximum internal air temperature were slightly over- 
estimated by the model compared to the monitoring results, resulting in a higher decrement factor (c. $40 \%$ higher average $\mathrm{D}_{\mathrm{f}}$ provided by the simulation model in comparison to reality). Moreover, the simulation results under-estimated the decrement delay during both warm and cold periods under investigation, indicating a shortcoming of the models.

\subsection{The impact of varying thermal mass}

The comparison of ICF, HTM and LTM buildings confirmed the findings of previous studies [18][20][25], i.e. that thermal performance of ICF sits between the other two construction methods. The diurnal temperature variation of the ICF building showed slightly increased peaks of maximum in comparison to the HTM building, but overall the two buildings performed very similarly. Surprisingly, the LTM building was found to have a similar diurnal temperature profile to the other two construction methods, although one would expect its decrement factor to be significantly higher than heavyweight structures, with a smaller time lag, resembling the diurnal temperature variation of ambient air. This was proven to be mainly attributed to the heavyweight construction of the ground floor slab, which was kept the same in all three buildings. Furthermore, the results of the analysis showed that the dampening effect of the ICF building in internal air temperature swings was very much affected by the thermal mass of the floor construction. Nevertheless, during warm weather, regardless of the floor construction, the thermal storage capacity of the ICF walls resulted in an average of $2^{\circ} \mathrm{C}$ reduction in the internal air temperatures compared to the LTM building.

The decrement factor of the HTM building was the smallest of the three cases, during both warm and cold weather. The ICF building showed a comparable decrement factor to the LTM building during both periods of analysis, indicating that the thermal storage capacity of the ICF walls had no significant impact on a daily temperature variation cycle. The reduction of zone mean air temperatures by $2^{\circ} \mathrm{C}$ in the ICF building however, when compared to the LTM building during warm period, showed that the thermal inertia of the ICF concrete core affected the overall thermal storage of the walls in longer cycles (i.e. weekly or seasonally) and had consequently an impact on the internal air temperatures. A finding which was further enhanced by the results of the sensitivity analysis.

\subsection{Sensitivity analysis of wall material properties}

The SA for the ICF building, indicated that among the wall material properties, the density, specific heat capacity and thickness of the concrete core were the most influential parameters (with regards to the zone mean air temperature during both warm and cold weather). In other words, the SA showed that the thermal storage capacity of the ICF concrete core is not as thermally decoupled from the internal space as one would expect and it does affect the internal air temperatures in the building. This finding becomes particularly relevant when considering several simplified methods used for the calculation of energy use in buildings for compliance, such as the BS EN ISO 13790: 2008 [52] and the UK Government's standard assessment procedure for energy rating of dwellings (SAP2012) [53]. Taking SAP as an example, to calculate the thermal mass parameter of an element, one needs to calculate the heat capacity of all its layers. 
However, it is specifically stated that starting from the internal surface, the calculations should stop when one of the following conditions occurs:

- an insulation layer (thermal conductivity $<=0.08 \mathrm{~W} / \mathrm{m} \cdot \mathrm{K}$ ) is reached;

- $\quad$ total thickness of $100 \mathrm{~mm}$ is reached.

- $\quad$ half way through the element;

Similarly in ISO 13790: 2008, the internal heat capacity of the building is calculated by summing up the heat capacities of all the building elements for a maximum effective thickness of $100 \mathrm{~mm}$. In other words, according to SAP and ISO 13790 the thermal storage capacity of ICF concrete core should be completely disregarded, which this research has clearly shown to be problematic. The results of this analysis indicate that ICF could be a viable alternative for energy efficient construction. However, the study has also shown that the use of reliable, validated dynamic whole building simulation is imperative in order to evaluate accurately the thermal performance of new construction methods, of which there is currently little empirical knowledge.

\subsection{Heat flux analysis}

To investigate the thermal storage capacity of the ICF wall component further, the transient performance of the ICF wall was analysed by looking at internal surface and intra-fabric temperatures alongside the internal surface heat flux as recorded by the monitoring study and based on simulation predictions. The analysis showed that the concrete core of the ICF wall was kept at a relatively constant temperature, acting as a buffer to heat flowing in and out of the building. In the comparison of ICF and LTM buildings, the concrete core of ICF resulted in reduced heat losses from the internal space towards the exterior environment. Considering that the only difference among the two wall construction methods was the level of thermal mass due to the concrete core (same U-value, same internal and external surface materials), then this reduction of heat losses can be solely attributed to the thermal inertia of the ICF concrete core. Reilly and Kinnane [2] introduced the concept of Transient Energy Ratio (TER), in order to assess the role of thermal mass. According to them, the role of thermal mass can be assessed by comparing an accurate, transient model which accounts for thermal mass effects, to a static model of the same scenario.

$$
T E R=\frac{\text { Energy used in transient model }}{\text { Energy used in a static model }}
$$

Applying the TER to this research, the transient energy ratio measured the energy flow through the ICF wall, divided by the energy flow through a LTM wall (with the same thermal resistance but zero heat capacity, i.e. no thermal mass). The results indicated a TER $=0.63$. In other words, in the comparison of ICF to LTM building the thermal inertia of the ICF concrete core resulted in $37 \%$ less heat losses to the exterior. 
Finally, the comparison of ICF to the HTM building indicated that the internal insulation layer of the ICF reduces the admittance of the wall considerably and moderates its ability to capture and store internal heat gains during times of surplus. Consequently, depending on the use, the design and the location of the building, ICF could be more vulnerable to overheating compared to a HTM building. For the specific case study however, the analysis showed that a high thermal mass floor construction is able to stabilise the internal air temperature significantly, even when the walls are lightweight. Considering that one of the advantages of ICF in comparison to lightweight MMCs is its structural ability to support heavyweight floors, the overall thermal mass of the whole structure could be significantly increased.

\section{Research Limitations}

The analysis presented in this paper focused on the thermal performance of ICF in terms of internal air temperature. To investigate how the fabric would perform (with regard to internal air temperatures) it was essential to focus on periods without space conditioning, when the house was performing under a free-floating mode. Hence, two, one week long periods were included, when the house was unoccupied, one during summer warm weather and one during spring cold weather. This however, prevented several important factors related to thermal mass from being analysed, such as the impact of variable internal gains and air flows, the impact of intermittent occupation, the risk of overheating and others. Comparing the relative performance of the ICF building against the other two construction methods showed that, for this specific case study, the former behaves closer to the HTM building. However, extending the analysis to also include occupied periods, could improve the reliability of this outcome.

The cold unoccupied period included in the analysis was during a week in April 2017. For the purposes of this study it was crucial to investigate the performance of the fabric, when the house operated in free-floating mode. The ambient temperatures during April of 2017 were low enough to consider this period as a representative cold period. However, the availability of solar radiation was higher when compared to a typical winter week. This resulted in higher internal air temperatures than normally expected for a free-floating building operation in the winter period. It would enhance the reliability of the research findings, if the cold period analysis was repeated for an unoccupied week in the winter months (i.e. December to February).

A further limitation of the study was that during the monitoring period, only global horizontal radiation was recorded on site. The split between direct normal and diffuse horizontal components was performed in EnergyPlus using the Perez model [31]. This however introduces a certain level of modelling uncertainty, since there are no monitoring data available to use as a reference point for direct and diffuse radiation values used in the simulation.

The internal air temperature was measured in one location within each room, using HOBO U12 stand-alone loggers. The loggers were placed at a height of $1.5 \mathrm{~m}$ from the floor, away from heat sources and direct solar radiation, as 
suggested in literature [5][54]. However, this decision does not account for the effects of air stratification that may arise in the room due to buoyancy. It may also introduce a systematic error in the results, which would be significantly reduced if more than one sensor had been placed per room and their average was used to calculate the zone mean air temperature, instead of the values from a single logger.

\section{Conclusions}

This research was set out to evaluate the internal thermal conditions of an ICF building and to investigate the contribution (or otherwise) of the thermal storage capacity of the ICF concrete core to the transient heat flow in and out of the building. The study followed a stratified research approach, including:

1) Field-study analysis/ empirical evaluation of a real ICF building to collect high resolution data on the whole building performance (i.e. internal air temperature, energy consumption, dynamic performance of building fabric), which would serve as a reference point to validate the accuracy of simulation output against.

2) Calibrated, empirically validated simulation, which framed the basis for understanding the key features associated to thermal mass, such as the transient heat transmission in and out of the building and the sensitivity of the internal environment to the physical properties of the construction related to its thermal storage capacity.

By doing this, a new procedure was presented for proofing the thermal storage capacity of new and innovative materials, where their thermal performance is not yet well-researched. This was tested using ICF. The internal layer of insulation in the ICF assembly, reduces the thermal admittance of the wall, making it difficult to quantify the actual thermal mass potentials of the element. Hence based on simplified calculation methods, ICF would be characterised as a thermally lightweight structure. The work reported here, followed a number of steps and proved that the element's concrete core is not as thermally decoupled from the internal space as has been thought to be the case. Rather, the concrete core of the ICF element was found to act as a buffer to the heat flow that occurs in and out of the building. Due to its thermal inertia the concrete was kept at a relatively constant temperature, thereby reducing transmission losses and gains (compared to a low thermal mass wall with equal levels of insulation). Undoubtedly, the internal insulation layer reduced the admittance of the wall, so decreasing the amount of heat penetrating the ICF fabric (compared to a similar wall with exposed thermal mass). Therefore, a higher risk of overheating might be anticipated for an ICF building compared to a high thermal mass building in scenarios with increased internal loads or in a building located in warmer climates than the UK.

In addition, the findings of this study showed that simplified calculation methods commonly used in industry to demonstrate regulatory compliance could be inaccurate for new and innovative construction methods. This could 
potentially lead to misconceptions about their thermal behaviour and affect their market penetration. Therefore, the use of reliable dynamic whole building simulation is necessary in order to evaluate accurately the thermal performance of specific buildings and non-conventional construction methods. Previous research has showed that the divergence in the simulation predictions provided by different tools for the same ICF building could be as high as $26 \%$, when users rely on default settings and input values [25]. This paper has shown that if the ICF building is correctly represented in BPS, (i.e. with correct input values representing its actual performance and suitable selection of calculation algorithms), then the BPS models are able to predict the thermal performance of the building with a good accuracy. While there was a discrepancy in the calculation of the fabric's dynamic characteristics (decrement factor $\mathrm{D}_{\mathrm{f}}$ and decrement delay $\omega$ ), the simulation models showed an overall good representation of reality with regards to diurnal temperature variations.

\section{Acknowledgements}

The authors gratefully acknowledge the Engineering and Physical Sciences Research Council and the Centre for Innovative and Collaborative Construction Engineering at Loughborough University for the provision of a grant (number EPG037272) to undertake this research project, in collaboration with Aggregate Industries UK Ltd. Furthermore, they would like to thank Mr and Mrs Karlsson for their kindness to offer their house for the monitoring project, and Mr Vince Smedley for advising and installing the monitoring equipment.

\section{References}

[1] R.S. McLeod, C.J. Hopfe, Hygrothermal implications of low and zero energy standards for building envelope performance in the UK, J. Build. Perform. Simul. 6 (2013) 367-384. doi:10.1080/19401493.2012.762809.

[2] A. Reilly, O. Kinnane, The impact of thermal mass on building energy consumption, Appl. Energy. 198 (2017) 108-121. doi:10.1016/j.apenergy.2017.04.024.

[3] S. A. Al-Sanea, M.F. Zedan, Improving thermal performance of building walls by optimizing insulation layer distribution and thickness for same thermal mass, Appl. Energy. 88 (2011) 3113-3124. doi:10.1016/j.apenergy.2011.02.036.

[4] L. Navarro, A. de Gracia, D. Niall, A. Castell, M. Browne, S.J. McCormack, P. Griffiths, L.F. Cabeza, Thermal energy storage in building integrated thermal systems: A review. Part 2. Integration as passive system, Renew. Energy. 85 (2016) 1334-1356. doi:10.1016/j.renene.2015.06.064.

[5] S. Kumar, P. Tewari, S. Mathur, J. Mathur, Development of mathematical correlations for indoor temperature from field observations of the performance of high thermal mass buildings in India, Build. Environ. 122 (2017) 324-342. doi:10.1016/j.buildenv.2017.06.030.

[6] C. Kendrick, R. Ogden, X. Wang, B. Baiche, Thermal mass in new build UK housing: A comparison of structural systems in a future weather scenario, Energy Build. 48 (2012) 40-49. doi:10.1016/j.enbuild.2012.01.009.

[7] I. Dincer, M. Rosen, Thermal Energy Storage Systems and Applications, 2011.

[8] C.J. Hopfe, R.S. McLeod, The passivhaus designer's manual a technical guide to low and zero energy buildings, 1st ed., New York, 2015.

[9] C.A. Balaras, The role of thermal mass on the cooling load of buildings. An ovrview of computational methods, 
Energy Build. 24 (1996).

[10] L.T. Rodrigues, An investigation into the use of thermal mass to improve comfort in British housing. PhD Thesis, University of Nottingham, 2009.

[11] W. Pan, A.G.F. Gibb, A.R.J. Dainty, Perspectives of UK housebuilders on the use of offsite modern methods of construction, Constr. Manag. Econ. 25 (2007) 183-194. doi:10.1080/01446190600827058.

[12] NHBC_Foundation, Modern Methods of Construction: views from the industry, 2016. ISBN 987-1-84806-4447.

[13] N. Rajagopalan, M.M. Bilec, A.E. Landis, Comparative life cycle assessment of insulating concrete forms with traditional residential wall sections, 2009 IEEE Int. Symp. Sustain. Syst. Technol. ISSST '09 Coop. with 2009 IEEE Int. Symp. Technol. Soc. ISTAS. (2009). doi:10.1109/ISSST.2009.5156707.

[14] NAHB, Insulating Concrete Forms: Comparative Thermal Performance. US Dept. of Housing and Urban Development, 1999.

[15] D. Hill, R. Monsour, Monitored Performance of an Insulating Concrete Form Multi-Unit Residential Building, Canada, 2007.

[16] M.M. Armstrong, W. Maref, H.H. Saber, M.Z. Rousseau, G. Ganapathy, M.C. Swinton, The impact of the thermal mass on field energy performance of insulating concrete form (ICF) wall, Canada, 2011.

[17] J. Gajda, M. VanGeem, Energy use in residential housing: A comparison of insulating concrete form and wood frame walls, Protl. Cem. Assoc, 2000.

[18] J. Kosny, T. Petrie, D. Gawin, P. Childs, A. Desjarlais, J. Christian, Energy Savings Potential in Residential Buildings, USA: Oak Ridge National Laboratory, 2001.

[19] H.H. Saber, W. Maref, M.M. Armstrong, M.C. Swinton, M.Z. Rousseau, G. Gnanamurugan, Numerical Simulations to Predict the Thermal Response of Insulating Concrete Form ( ICF ) Wall in Cold Climate, 2011.

[20] R. Hart, V. Mendon, T. Taylor, Florida Masonry Apprentices \& Educational Foundation, Residential Wall Type Energy Impact Analysis, 2014.

[21] J. Kośny, E. Kossecka, Multi-dimensional heat transfer through complex building envelope assemblies in hourly energy simulation programs, Energy Build. 34 (2002) 445-454. doi:10.1016/S0378-7788(01)00122-0.

[22] E. Mantesi, C.J. Hopfe, J. Glass, M. Cook, Assessment of ICF Energy Saving Potential in Whole Building Performance Simulation Tools, 14th Build. Simul. Conf. Hyderabad, 07-09 December 2015, India. 2015.

[23] E. Mantesi, C.J. Hopfe, J. Glass, M. Cook, Investigating the impact of modelling uncertainty on the simulation of insulating concrete formwork for buildings, in: Proc. 3rd IBPSA-Engl. Conf. BSO 2016, 2016.

[24] K. Mourkos, E. Mantesi, C.J. Hopfe, M.J. Cook, J. Glass, C. Goodier, The Role of Fabric Performance in the Seasonal Overheating of Dwellings, in: 15 ${ }^{\text {th }}$ Build. Simul. 2017, San Fr. USA, 07 - 09 Aug 2017, 2017.

[25] E. Mantesi, C.J. Hopfe, M.J. Cook, J. Glass, P. Strachan, The modelling gap: Quantifying the discrepancy in the representation of thermal mass in building simulation, Build. Environ. (2018) 74-98. doi:10.1016/j.buildenv.2017.12.017.

[26] D. Coakley, P. Raftery, M. Keane, A review of methods to match building energy simulation models to measured data, Renew. Sustain. Energy Rev. 37 (2014) 123-141. doi:10.1016/j.rser.2014.05.007.

[27] Met Office, Met Office: weather and climate data, (n.d.). https://www.metoffice.gov.uk/ (accessed March 12, 2018).

[28] CIBSE, TM41:2006 Degree-days: Theory and application, London: The Chartered Institution of Building Services Engineers, 2006.

[29] GILL Instruments Limited, MaxiMet GMX501 Compact weather station, (2015). http:/gillinstruments.com/data/datasheets/maximet-gmx501.pdf?iss=1.20150501 (accessed March 12, 2018).

[30] Hekseflux Thermal Sensors User Manual SR03 Fast response second class pyranometer, (n.d.). https://www.hukseflux.com/sites/default/files/product_manual/SR05_manual_v1610.pdf (accessed March 12, 2018). 
[31] R. Perez, Dynamic global-to-direct irradiance conversion models, Ashrae. 98 (1992) 354-369.

[32] DOE, EnergyPlus Engineering Reference: The Reference to EnergyPlus Calculations, US Dep. Energy. 2010 1051. doi:citeulike-article-id:10579266.

[33] T. Sensors, Hukseflux Thermal Sensors User Manual HFP01 \& HFP03 Heat Flux Plate/ Heat Flux Sensor, (n.d.) 1-43. https://www.hukseflux.com/sites/default/files/product_manual/HFP01_HFP03_manual_v1721.pdf [Accessed on: (accessed March 12, 2018).

[34] HOBO U12 Temp/RH/Light/External Data (n.d.). http://www.onsetcomp.com/files/manual_pdfs/13128-C U12-012 Manual.pdf (accessed March 12, 2018).

[35] T.A. Reddy, Literature review on calibration of building energy simulation programs: Uses, problems, procedures, uncertainty, and tools., ASHRAE Trans. 112 (2006) 226-240.

[36] ASHRAE, ASHRAE Handbook - Fundamentals, Atlanta, GA: American Society of Heating, Refrigerating and Air-Conditioning Engineers, 2009.

[37] S. Wang, C. Yan, F. Xiao, Quantitative energy performance assessment methods for existing buildings, Energy Build. 55 (2012) 873-888. doi:10.1016/j.enbuild.2012.08.037.

[38] S.J. Emmerich, A.K. Persily, Analysis of US Commercial Building Envelope Air Leakage Database to Support Sustainable Building Design, Int. J. Vent. 12 (2014) 331-343. doi:10.5555/2044-4044-12.4.331.

[39] N. Fumo, A review on the basics of building energy estimation, Renew. Sustain. Energy Rev. 31 (2014) 53-60. doi:10.1016/j.rser.2013.11.040.

[40] G. Mustafaraj, D. Marini, A. Costa, M. Keane, Model calibration for building energy efficiency simulation, Appl. Energy. 130 (2014) 72-85. doi:10.1016/j.apenergy.2014.05.019.

[41] J.C. Helton, F.J. Davis, Latin hypercube sampling and the propagation of uncertainty in analyses of complex systems, Reliab. Eng. Syst. Saf. 81 (2003) 23-69. doi:10.1016/S0951-8320(03)00058-9.

[42] A. Saltelli, S. Tarantola, F. Campolongo, M. Ratto, Sensitivity analysis in practice : a guide to assessing scientific models, John Wiley, Chichester, 2004.

[43] C.J. Hopfe, Uncertainty and sensitivity analysis in building performance simulation for decision support and design optimization. PhD Thesis, Eidhoven University of Technology, 2009.

[44] SimLab, SimLab 2.2, Reference Manual, (n.d.). https://ec.europa.eu/jrc/en/samo/simlab (accessed March 12, 2018).

[45] H. Johra, P. Heiselberg, Influence of internal thermal mass on the indoor thermal dynamics and integration of phase change materials in furniture for building energy storage: A review, Renew. Sustain. Energy Rev. 69 (2017) 19-32. doi:10.1016/j.rser.2016.11.145.

[46] JEPlus, jEPlus User's Manual, Version 1.4, (n.d.). http://www.jeplus.org/wiki/doku.php?id=docs:manual_1_4 (accessed March 12, 2018).

[47] F. Campolongo, J. Cariboni, A. Saltelli, An effective screening design for sensitivity analysis of large models, Environ. Model. Softw. 22 (2007) 1509-1518. doi:10.1016/j.envsoft.2006.10.004.

[48] EVO, International Performance Measurement and Verification Protocol, Canada: Efficiency Valuation Organization, 2012. doi:10.1126/science.15.390.961.

[49] ASHRAE, Guideline 14 - 2014: Measurement of Energy Demand and Water Savings, Atlanda, GA: American Society of Heating, Refrigerating and Air-Conditioning Engineers, 2014.

[50] R.S. McLeod, C.J. Hopfe, A. Kwan, An investigation into future performance and overheating risks in Passivhaus dwellings, Build. Environ. 70 (2013) 189-209. doi:10.1016/j.buildenv.2013.08.024.

[51] E. Brembilla, J. Mardaljevic, C.J. Hopfe, Sensitivity Analysis Studying the Impact of Reflectance Values Assigned in Climate-Based Daylight Modelling, in: 14 ${ }^{\text {th }}$ Build. Simul. Conf. Hyderabad, 07-09 December 2015, India. 2015.

[52] BS EN ISO 13790:, Energy Performance of Buildings - calculation of energy use for space heating and cooling, Geneva, 2008. 
[53] BRE, SAP 2012 The Government's Standard Assessment Procedure for Energy Rating of Dwellings, London, 2012. doi:10.1007/s13398-014-0173-7.2.

[54] M.K. Singh, S. Mahapatra, S.K. Atreya, B. Givoni, Thermal monitoring and indoor temperature modeling in vernacular buildings of North-East India, Energy Build. 42 (2010) 1610-1618. doi:10.1016/j.enbuild.2010.04.003. 


\section{Appendix}

Table A. 1 Thermal properties of all three wall construction materials included in the analysis (i.e. ICF, HTM, LTM)

\begin{tabular}{|c|c|c|c|c|c|c|c|}
\hline \multicolumn{2}{|c|}{$\begin{array}{l}\text { Element } \\
\text { (outside to inside) }\end{array}$} & \multirow{2}{*}{$\begin{array}{l}\text { Thickness } \\
\text { (mm) } \\
3\end{array}$} & \multirow{2}{*}{$\begin{array}{l}\text { Conductivity } \\
\text { (W/mK) } \\
0.8\end{array}$} & \multirow{2}{*}{$\begin{array}{l}\text { Density } \\
\left(\mathbf{k g} / \mathbf{m}^{\mathbf{3}}\right)\end{array}$} & \multirow{2}{*}{$\begin{array}{l}\text { Specific } \\
\text { Heat } \\
\text { Capacity } \\
\text { (J/kgK) } \\
650\end{array}$} & \multirow{2}{*}{$\begin{array}{l}\begin{array}{l}\text { Diffusivity } \\
\left(\mathrm{mm}^{2} / \mathrm{s}\right)\end{array} \\
0.586\end{array}$} & \multirow[t]{2}{*}{$\begin{array}{l}\text { U-Value } \\
\left(\mathbf{W} / \mathbf{m}^{2} \mathbf{K}\right)\end{array}$} \\
\hline ICF & Cement Screed & & & & & & \\
\hline & Cement Plaster & 3 & 0.72 & 1760 & 840 & 0.487 & \\
\hline & EPS Insulation & 210 & 0.037 & 25 & 1400 & 1.057 & \\
\hline & Cast Concrete & 147 & 2 & 2300 & 1000 & 0.87 & \\
\hline & EPS Insulation & 108 & 0.037 & 25 & 1400 & 1.057 & \\
\hline & Plasterboard & 13 & 0.21 & 950 & 840 & 0.2632 & \\
\hline Total & & & & & & & 0.113 \\
\hline \multirow{5}{*}{$\begin{array}{l}\text { HTM } \\
\text { Wall }\end{array}$} & Cement Screed & 3 & 0.8 & 2100 & 650 & 0.586 & \\
\hline & Cement Plaster & 3 & 0.72 & 1760 & 840 & 0.487 & \\
\hline & EPS Insulation & 318 & 0.037 & 25 & 1400 & 1.057 & \\
\hline & Cast Concrete & 147 & 2 & 2300 & 1000 & 0.87 & \\
\hline & Plasterboard & 13 & 0.21 & 950 & 840 & 0.2632 & \\
\hline Total & & & & & & & 0.113 \\
\hline \multirow{4}{*}{$\begin{array}{l}\text { LTM } \\
\text { Wall }\end{array}$} & Cement Screed & 3 & 0.8 & 2100 & 650 & 0.586 & \\
\hline & Cement Plaster & 3 & 0.72 & 1760 & 840 & 0.487 & \\
\hline & EPS Insulation & 318 & 0.037 & 25 & 1400 & 1.057 & \\
\hline & Plasterboard & 13 & 0.21 & 950 & 840 & 0.2632 & \\
\hline Total & & & & & & & 0.115 \\
\hline
\end{tabular}


Table A.2 Thermal properties of floor construction materials included in the parametric analysis.

\begin{tabular}{|c|c|c|c|c|c|}
\hline \multicolumn{2}{|c|}{ Element (from Outside to Inside) } & \multirow{2}{*}{$\begin{array}{l}\begin{array}{l}\text { Thickness } \\
(\mathbf{m m})\end{array} \\
300 \\
50 \\
5 \\
350 \\
25\end{array}$} & \multirow{2}{*}{$\begin{array}{l}\begin{array}{l}\text { Conductivity } \\
\text { (W/mK) }\end{array} \\
1.802 \\
1.73 \\
0.19 \\
0.037 \\
0.14\end{array}$} & \multirow{2}{*}{$\begin{array}{l}\begin{array}{l}\text { Density } \\
\left(\mathbf{k g} / \mathbf{m}^{\mathbf{3}}\right)\end{array} \\
2243 \\
2243 \\
1121 \\
25 \\
650\end{array}$} & \multirow{2}{*}{$\begin{array}{l}\begin{array}{l}\text { Specific Heat } \\
\text { (J/kgK) }\end{array} \\
837 \\
837 \\
1647 \\
1400 \\
1200\end{array}$} \\
\hline $\begin{array}{l}\text { LTM/ } \\
\text { ICF } \\
\text { Lightweight } \\
\text { Ground Floor }\end{array}$ & $\begin{array}{l}\text { Stone Bed } \\
\text { Blinding Layer } \\
\text { Membrane } \\
\text { EPS Insulation } \\
\text { Timber Flooring }\end{array}$ & & & & \\
\hline $\begin{array}{l}\text { ICF } \\
\text { Mediumweight } \\
\text { Ground Floor }\end{array}$ & $\begin{array}{l}\text { Stone Bed } \\
\text { Blinding Layer } \\
\text { Membrane } \\
\text { EPS Insulation } \\
\text { Mediumweight } \\
\text { Concrete Slab }\end{array}$ & $\begin{array}{l}300 \\
50 \\
5 \\
350 \\
150\end{array}$ & $\begin{array}{l}1.802 \\
1.73 \\
0.19 \\
0.037 \\
0.2\end{array}$ & $\begin{array}{l}2243 \\
2243 \\
1121 \\
25 \\
600\end{array}$ & $\begin{array}{l}837 \\
837 \\
1647 \\
1400 \\
840\end{array}$ \\
\hline $\begin{array}{l}\text { HTM/ ICF } \\
\text { Heavyweight } \\
\text { Ground Floor }\end{array}$ & $\begin{array}{l}\text { Stone Bed } \\
\text { Blinding Layer } \\
\text { Membrane } \\
\text { EPS Insulation } \\
\text { Concrete Slab }\end{array}$ & $\begin{array}{l}300 \\
50 \\
5 \\
350 \\
150\end{array}$ & $\begin{array}{l}1.802 \\
1.73 \\
0.19 \\
0.037 \\
2\end{array}$ & $\begin{array}{l}2243 \\
2243 \\
1121 \\
25 \\
2300\end{array}$ & $\begin{array}{l}837 \\
837 \\
1647 \\
1400 \\
1000\end{array}$ \\
\hline
\end{tabular}

Table A. 3 Description of the interior mass material properties included in the uncertainty analysis; mean $(\mu)$ and uniform distribution ranges.

\begin{tabular}{|l|c|c|}
\hline \multicolumn{3}{|c|}{ Interior mass material properties } \\
\hline \multirow{2}{*}{ Thickness } & $\mu$ & 0.5 \\
\cline { 2 - 3 } & $\mathrm{U}$ & {$[0.25,0.75]$} \\
\hline \multirow{2}{*}{ Conductivity } & $\mu$ & 0.2 \\
\cline { 2 - 3 } & $\mathrm{U}$ & {$[0.1,0.3]$} \\
\hline \multirow{2}{*}{ Density } & $\mu$ & 800 \\
\cline { 2 - 3 } & $\mathrm{U}$ & {$[400,1200]$} \\
\hline \multirow{2}{*}{ Specific Heat Capacity } & $\mu$ & 1400 \\
\cline { 2 - 4 } & $\mathrm{U}$ & {$[700,2100]$} \\
\hline \multirow{2}{*}{ Area $^{8}$} & $\mu$ & 8.5 \\
\cline { 2 - 4 } & $\mathrm{U}$ & {$[3.36,16.8]$} \\
\hline
\end{tabular}

\footnotetext{
${ }^{8}$ The uncertainty range in the area of the interior mass represents a uniform distribution with minimum $10 \%$ coverage and maximum $50 \%$ of the total floor area of the zone.
} 
Table A. 4 Description of the material properties included in the sensitivity analysis; mean ( $\mu$ ) and uniform distribution ranges.

\begin{tabular}{|c|c|c|c|c|c|}
\hline \multicolumn{2}{|l|}{ ICF Wall } & $\begin{array}{c}\mathrm{d} \\
(\mathrm{mm})\end{array}$ & $\begin{array}{c}\lambda \\
(\mathrm{W} / \mathrm{mK})\end{array}$ & $\begin{array}{c}\rho \\
\left(\mathrm{kg} / \mathrm{m}^{3}\right)\end{array}$ & $\begin{array}{c}\mathrm{c} \\
(\mathrm{J} / \mathrm{kgK})\end{array}$ \\
\hline \multirow[t]{2}{*}{ Cement Screed } & $\mu$ & 0.003 & 0.8 & 2100 & 650 \\
\hline & $\mathrm{U}$ & {$[0.0027,0.0033]$} & {$[0.72,0.88]$} & {$[1890,2310]$} & {$[585,715]$} \\
\hline \multirow{2}{*}{ Cement Plaster } & $\mu$ & 0.003 & 0.72 & 1760 & 840 \\
\hline & $\mathrm{U}$ & {$[0.0027,0.0033]$} & {$[0.648,0.792]$} & {$[1584,1936]$} & {$[756,924]$} \\
\hline \multirow[t]{2}{*}{ EPS Insulation } & $\mu$ & 0.210 & 0.037 & 25 & 1400 \\
\hline & $\mathrm{U}$ & {$[0.189,0.231]$} & {$[0.033,0.041]$} & {$[22.5,27.5]$} & {$[1260,1540]$} \\
\hline \multirow[t]{2}{*}{ Cast Concrete } & $\mu$ & 0.147 & 2.00 & 2300 & 1000 \\
\hline & $\mathrm{U}$ & {$[0.1323,0.1617]$} & {$[1.8,2.2]$} & {$[2070,2530]$} & {$[900,1100]$} \\
\hline \multirow[t]{2}{*}{ EPS Insulation } & $\mu$ & 0.108 & 0.037 & 25 & 1400 \\
\hline & $\mathrm{U}$ & {$[0.0972,0.1188]$} & {$[0.033,0.041]$} & {$[22.5,27.5]$} & {$[1260,1540]$} \\
\hline \multirow{2}{*}{ Plasterboard } & $\mu$ & 0.013 & 0.21 & 950 & 840 \\
\hline & $\mathrm{U}$ & {$[0.0117,0.0143]$} & {$[0.189,0.231]$} & {$[855,1045]$} & {$[756,924]$} \\
\hline \multicolumn{6}{|l|}{ HTM Wall } \\
\hline \multirow[t]{2}{*}{ Cement Screed } & $\mu$ & 0.003 & 0.8 & 2100 & 650 \\
\hline & $\mathrm{U}$ & {$[0.0027,0.0033]$} & {$[0.72,0.88]$} & {$[1890,2310]$} & {$[585,715]$} \\
\hline \multirow[t]{2}{*}{ Cement Plaster } & $\mu$ & 0.003 & 0.72 & 1760 & 840 \\
\hline & $\mathrm{U}$ & {$[0.0027,0.0033]$} & {$[0.648,0.792]$} & {$[1584,1936]$} & {$[756,924]$} \\
\hline \multirow[t]{2}{*}{ EPS Insulation } & $\mu$ & 0.318 & 0.037 & 25 & 1400 \\
\hline & $\mathrm{U}$ & {$[0.2862,0.3498]$} & {$[0.033,0.041]$} & {$[22.5,27.5]$} & {$[1260,1540]$} \\
\hline \multirow[t]{2}{*}{ Cast Concrete } & $\mu$ & 0.147 & 2.00 & 2300 & 1000 \\
\hline & $\mathrm{U}$ & {$[0.1323,0.1617]$} & {$[1.8,2.2]$} & {$[2070,2530]$} & {$[900,1100]$} \\
\hline \multirow[t]{2}{*}{ Plasterboard } & $\mu$ & 0.013 & 0.21 & 950 & 840 \\
\hline & $\mathrm{U}$ & {$[0.0117,0.0143]$} & {$[0.189,0.231]$} & {$[855,1045]$} & {$[756,924]$} \\
\hline \multicolumn{6}{|l|}{ LTM Wall } \\
\hline \multirow[t]{2}{*}{ Cement Screed } & $\mu$ & 0.003 & 0.8 & 2100 & 650 \\
\hline & $\mathrm{U}$ & {$[0.0027,0.0033]$} & {$[0.72,0.88]$} & {$[1890,2310]$} & {$[585,715]$} \\
\hline \multirow[t]{2}{*}{ Cement Plaster } & $\mu$ & 0.003 & 0.72 & 1760 & 840 \\
\hline & $\mathrm{U}$ & {$[0.0027,0.0033]$} & {$[0.648,0.792]$} & {$[1584,1936]$} & {$[756,924]$} \\
\hline \multirow[t]{2}{*}{ EPS Insulation } & $\mu$ & 0.318 & 0.037 & 25 & 1400 \\
\hline & $\mathrm{U}$ & {$[0.2862,0.3498]$} & {$[0.033,0.041]$} & {$[22.5,27.5]$} & {$[1260,1540]$} \\
\hline \multirow[t]{2}{*}{ Plasterboard } & $\mu$ & 0.013 & 0.21 & 950 & 840 \\
\hline & $\mathrm{U}$ & {$[0.0117,0.0143]$} & {$[0.189,0.231]$} & {$[855,1045]$} & {$[756,924]$} \\
\hline
\end{tabular}

